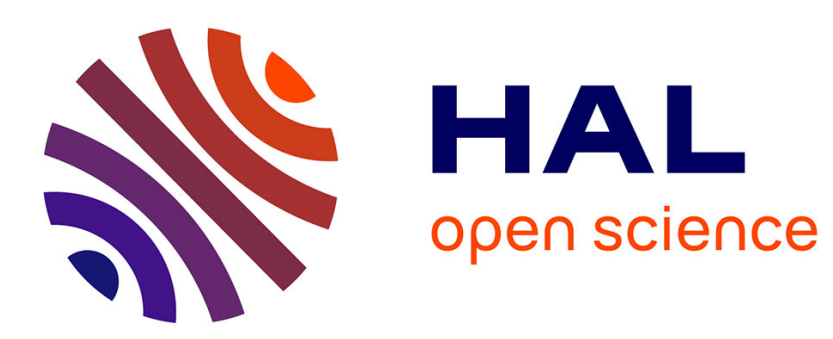

\title{
Obodji Soboa, chef supérieur des Abbey en Côte d'Ivoire coloniale
}

Marie Miran-Guyon

\section{To cite this version:}

Marie Miran-Guyon. Obodji Soboa, chef supérieur des Abbey en Côte d'Ivoire coloniale. Afrique Contemporaine, 2018, N²67-268 (3), pp.221. 10.3917/afco.267.0221 . halshs-02508368

\section{HAL Id: halshs-02508368 \\ https://shs.hal.science/halshs-02508368}

Submitted on 17 Mar 2020

HAL is a multi-disciplinary open access archive for the deposit and dissemination of scientific research documents, whether they are published or not. The documents may come from teaching and research institutions in France or abroad, or from public or private research centers.
L'archive ouverte pluridisciplinaire HAL, est destinée au dépôt et à la diffusion de documents scientifiques de niveau recherche, publiés ou non, émanant des établissements d'enseignement et de recherche français ou étrangers, des laboratoires publics ou privés. 


\title{
OBODJI SOBOA, CHEF SUPÉRIEUR DES ABBEY EN CÔTE D’IVOIRE COLONIALE
}

La mémoire oubliée d’un homme puissant

\author{
Marie Miran-Guyon
}

De Boeck Supérieur | «Afrique contemporaine »

2018/3 N²67-268 | pages 221 à 249

ISSN 0002-0478

ISBN 9782807391741

Article disponible en ligne à l'adresse :

https://www.cairn.info/revue-afrique-contemporaine-2018-3-page-221.htm

Distribution électronique Cairn.info pour De Boeck Supérieur.

(C) De Boeck Supérieur. Tous droits réservés pour tous pays.

La reproduction ou représentation de cet article, notamment par photocopie, n'est autorisée que dans les limites des conditions générales d'utilisation du site ou, le cas échéant, des conditions générales de la licence souscrite par votre établissement. Toute autre reproduction ou représentation, en tout ou partie, sous quelque forme et de quelque manière que ce soit, est interdite sauf accord préalable et écrit de l'éditeur, en dehors des cas prévus par la législation en vigueur en France. Il est précisé que son stockage dans une base de données est également interdit. 


\title{
Obodji Soboa, chef supérieur des Abbey en Côte d'Ivoire coloniale La mémoire oubliée d'un homme puissant
}

\author{
Marie Miran-Guyon
}

\begin{abstract}
Cet article brosse le portrait en clair-obscur d'un personnage influent mais oublié de l'histoire coloniale de la Côte d'Ivoire. Obodji Soboa (1886-1952) fut le chef supérieur des Abbey : l'un des rares chefs traditionnels du pays à s'élever à cette distinction la plus haute du " commandement indigène ". L'article interroge l'origine et la transformation du pouvoir dit " coutumier " d'Obodji Soboa et cartographie l'encablure de son autonomie sous contrainte. II documente aussi ses entreprises économiques et son Église prophétique originale, d'inspiration harriste, dite d'" Aké Offo ". L'article porte un soin particulier à la présentation et à la restitution des sources de l'étude, pour partie inédites, et revisite la question de l'interface entre histoire, mémoire et oubli.
\end{abstract}

Mots clés : Côte d'Ivoire - Abbey - Agboville - Chefferie traditionnelle-Prophétisme - Obodji Soboa - Bodjui Aké

À Claude-Hélène Perrot (1928-2019)

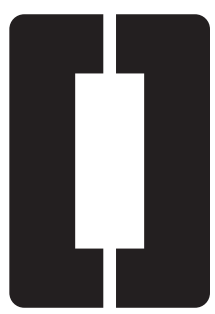

Obodji Soboa (c. 1886-1952) fut le chef supérieur des Abbey, dans la région d'Agboville, de 1923 à 1944 : l'un des cinq chefs traditionnels en Côte d'Ivoire coloniale élevés à cette dignité «exceptionnelle et rare $^{1} »$, summum du «commandement indigène » institutionnalisé par l'administration française en $1934^{2}$. Obodji Soboa partagea ce titre avec Boa Kouassi II, chef supérieur de l'Indenié, Kouadio Adjoumani, chef supérieur des Abron, Yaté N'guessan, chef supérieur des Attié, et Antonin Dioulo, chef supérieur des Ébrié. Obodji Soboa fut influent par-delà sa province. En paire avec Boa Kouassi, il fut élu délégué au Conseil du gouvernement de l'Afrique occidentale française pour la Côte d'Ivoire lors des premières élections incluant des représentants africains, en $1935^{3}$. Exploitant forestier, planteur, transporteur,

Marie Miran-Guyon est maître de conférences à l'EHESS et membre de I'IMAF à Paris. Ses premières recherches ont porté sur la culture islamique et la société musulmane de Côte d'Ivoire. Ses recherches actuelles interrogent la contribution globale et plurielle du champ religieux ivoirien à l'écriture du destin national, passé et présent. 
entrepreneur en bâtiments, commerçant et surtout fondateur d'une banque où il plaça sa richesse en or, Obodji Soboa «faisait partie du gotha financier de l'époque », selon les termes de Frédéric Grah Mel, biographe de Félix Houphouët-Boigny ${ }^{4}$. Il siégea au Conseil d'agriculture et d'industrie d'Abidjan. Le Syndicat agricole africain (SAA), premier syndicat de planteurs ivoiriens dirigé par Houphouët-Boigny, vit le jour à Agboville en 1944. En 1945, Obodji Soboa contribua à financer l'élection d'Houphouët-Boigny à l'Assemblée constituante à Paris et à lui rallier (temporairement) le soutien de Kouamé Adingra, fils du chef supérieur des Abron Kouadio Adjoumani ${ }^{5}$. Obodji Soboa fut aussi le chef religieux d'une Église prophétique africaine issue du harrisme, l'Église d'Aké $O f f_{o}$, qui fut décrite avec emphase comme un « culte national abbey ${ }^{6}$ » et « une religion d'État parmi les Abè ${ }^{7}$ », faisant d'Obodji Soboa un quasi-« prophète en son pays », le premier d'une longue liste dans l'histoire ivoirienne. Sur les plans croisés du succès économique et financier et de l'influence religieuse, Obodji Soboa le dispute au cheikh hamalliste Yacouba Sylla, qui fit fortune à Gagnoa dès les années $1930^{8}$.

La figure du chef Obodji Soboa est saisissante par son cumul des registres politique, économique et religieux de l'exercice de la puissance, à l'interface de la «tradition » africaine (en partie réinventée) et de la modernité coloniale (réappropriée et en partie détournée). Après l'écrasement des résistances anticoloniales suite à la «pacification » militaire du gouverneur Angoulvant à la charnière des années 1910, et avant les débuts du mouvement syndicaliste et

1. Loucou (2012, p. 110). Le chiffre de cinq chefs supérieurs concerne la période d'avant les années 1950. Par la suite, trois nouveaux chefs supérieurs furent encore nommés en pays baoulé, sanwi et sénoufo. Je remercie Jean-Noël Loucou pour sa relecture de cet article et ses remarques avisées.

2. Selon l'organisation officialisée par décret le 10 octobre 1934, mais qui s'était mise en place sur le terrain dès avant cette date, les chefs supérieurs aussi appelés chefs de provinces avaient autorité sur les chefs de cantons relevant de leurs provinces, ces derniers coiffant eux-mêmes les chefs de villages et de quartiers relevant de leurs cantons. Le territoire ivoirien totalisait 226 chefs de canton en 1934. Le cercle d'Agboville en comptait dix, dont les quatre cantons historiques abbey (Grah Mel, 2003, p. 165). En 2014, le recensement officiel de la population et de l'habitat dénombrait près de 215000 Abbey en Côte d'Ivoire, ce qui en fait le quatrième groupe akan le plus important du pays, loin derrière les Agni, Baoulé et Attié, légèrement devant les Abron.

3. Le Conseil de gouvernement de I'AOF était un organe consultatif local pour aviser le gouverneur de la colonie sur divers projets. Pour la première fois, en juillet 1935, les Africains citoyens français et les membres de l'élite africaine - chefs traditionnels, anciens combattants, lettrés - furent autorisés à élire l'un des leurs (Yeo, 2009, p. 128-129).

Binger écrivait plus laconiquement qu'Obodji Soboa était « conseiller du gouvernement » (Binger, 1938,

p. 254).

4. Grah Mel (2003, p. 268).

5. Grah Mel (2003, p. 255, 268 et

270).

6. Document de synthèse de

Niangoran-Bouah (1987, présenté ci-après).

7. Deschamps (1950), cité par Dozon (1995, p. 84). Les termes "nationaux » et «État» ne relèvent pas d'une description à la lettre - ils sont exogènes à la société (coloniale) abbey - mais ils dénotent bien

l'importance qu'eut un temps ce culte au plan régional.
8. De nombreux travaux ont été consacrés au cheikh Yacouba Sylla; voir par exemple Hanretta (2009).

9. Sur la capacité d'initiative (agency) des intermédiaires africains en contexte colonial, voir par exemple Lawrance, Osborn et Roberts (2006). 10. Dozon (1995, p. 83-84). Dozon écrit que Soboa «se prétend chef du peuple abè », a « un pouvoir incertain » (citant Deschamps, 1950) et (ne) doit sa richesse (qu') à la vente d'objets de culte.

11. Dans le cadre de nouvelles recherches pour une thèse d'HDR, dont l'inédit est provisoirement intitulé « Côte d'Ivoire. La fabrique religieuse d'une colonie

(1893-1960)".

12. Sur le personnage que fut Niangoran-Bouah sur la scène universitaire et politique ivoirienne, voir Perrot (2002), Duchesne (2002) et Arnaut (2008).

13. Tous mes remerciements à Albert Adja, Joachim Bilé-Aka, Edmond Codjo et Blé Akan Léonce Alban pour l'accès aux archives de Niangoran-Bouah à Abidjan, août 2019. 
nationaliste ivoirien au mitan des années 1940, soit dans la longue période de la pax colonia contemporaine de la « mise en valeur » de la colonie ivoirienne, Obodji Soboa fut un personnage baroque influent. Il témoigne de la capacité qu'eurent des élites, self-made-men et autres intermédiaires africains, à faire prospérer leurs propres initiatives, en dépit des relations de pouvoir asymétriques et des coercitions de la situation coloniale ${ }^{9}$.

Pourtant, sur ce personnage hors du commun, très peu a été publié. De rares études d'histoire coloniale mentionnent son nom ou lui consacrent à peine quelques lignes, en passant sous silence son épopée religieuse. L'ouvrage de Jean-Pierre Dozon sur les prophétismes ivoiriens lui dédie un gros paragraphe, essentiellement une citation de la voyageuse Clothilde Chivas-Baron (1939), en mettant en doute son influence politique et économique ${ }^{10}$.

C'est grâce à cette lecture et à plusieurs mémoires et thèses sur les christianismes ivoiriens au temps colonial que j'ai découvert le personnage ${ }^{11}$. Curieuse d'en apprendre davantage, je suis allée à la rencontre des descendants d’Obodji Soboa. Avec beaucoup de générosité, son arrière-petit-fils Léonard Obodji m'a donné accès à quelques documents écrits, photographiques et sonores issus des archives de la famille Obodji. Il a facilité mon accueil dans la cour familiale au quartier Obodjikro d'Agboville et la conduite sur place de quelques entretiens, principalement avec son oncle André Augustin Apété, petit-fils d'André Monsôh, neveu et proche collaborateur d'Obodji Soboa. Léonard Obodji m'a permis d'écouter deux longs enregistrements audio, l'un en français, l'autre en abbey (qu'il m'a traduit), fruit des enquêtes orales que conduisit l'anthropologue ivoirien Georges Niangoran-Bouah (1935-2002) en pays abbey dans les années $1980^{12}$. Niangoran-Bouah, dont on sait qu'il fut de mère et de culture abouré de Moossou, fut aussi, ce qui est moins connu, le fils de Meney [Monney], jeune frère d'Obodji Soboa, décédé prématurément à Dakar en 1938. Niangoran-Bouah, qui parlait l'abbey, conduisait des recherches sur l'histoire des migrations abbey et du lignage d'Obodji Soboa. Selon André Augustin Apété qui lui servit d'assistant localement, NiangoranBouah rédigea une monographie d'environ soixante-dix pages, qu'Apété relut et corrigea mais n'a pas conservée. Georges Niangoran-Bouah est décédé en 2002 et cette étude n'a jamais été publiée. Il en reste toutefois, dans les archives de la famille Obodji, un document de synthèse de neuf pages dactylographiées daté de 1987. J'ai mené des démarches auprès de la famille abouré de Georges Niangoran-Bouah qui m’a généreusement ouvert les portes de la bibliothèque de sa dernière résidence à Abidjan, où j'ai pu consulter ses archives personnelles, non classées ${ }^{13}$. Mais je n'y ai pas trouvé sa monographie sur les Abbey, dont j'espérais qu'elle pourrait faire l'objet d'une édition posthume (partie remise ?). J'ai en revanche trouvé d'autres choses, dont une liasse d'environ cent vingt pages que Niangoran-Bouah photocopia aux archives à Dakar en 1983.

Cet article se propose de dresser un portrait du chef Obodji Soboa au plus près de la documentation disparate à laquelle j'ai eu accès et qui fait une 
belle part à sa dimension religieuse. Son ambition est de partager ces sources et pistes de réflexion pour que d'autres poussent l'analyse plus avant, notamment dans les domaines qui me sont moins familiers : l'histoire économique et l'implication de la chefferie traditionnelle dans le mouvement syndical et nationaliste ivoirien à ses débuts.

Cet article adresse aussi une énigme. Comment se fait-il qu’un chef supérieur de cette carrure soit aujourd'hui si méconnu, voire complètement oublié ? Le portrait d'Obodji Soboa tenté dans les pages qui suivent est un tableau en clair-obscur, non seulement parce que la documentation est incomplète, mais aussi parce que certaines questions restent en suspens malgré la documentation disponible. Comment se fit-il, notamment, qu'un chef supérieur longtemps considéré comme un grand allié de la France, multi-médaillé, fut finalement désavoué, démis de ses fonctions et privé de sa succession? Vénéré par les uns, au premier chef ses fidèles religieux, abhorré et trahi par d'autres, en particulier des notables abbey, considéré comme charismatique ou tyrannique : Obodji Soboa fut assurément un personnage complexe et controversé, consumé peutêtre par sa propre flamboyance.

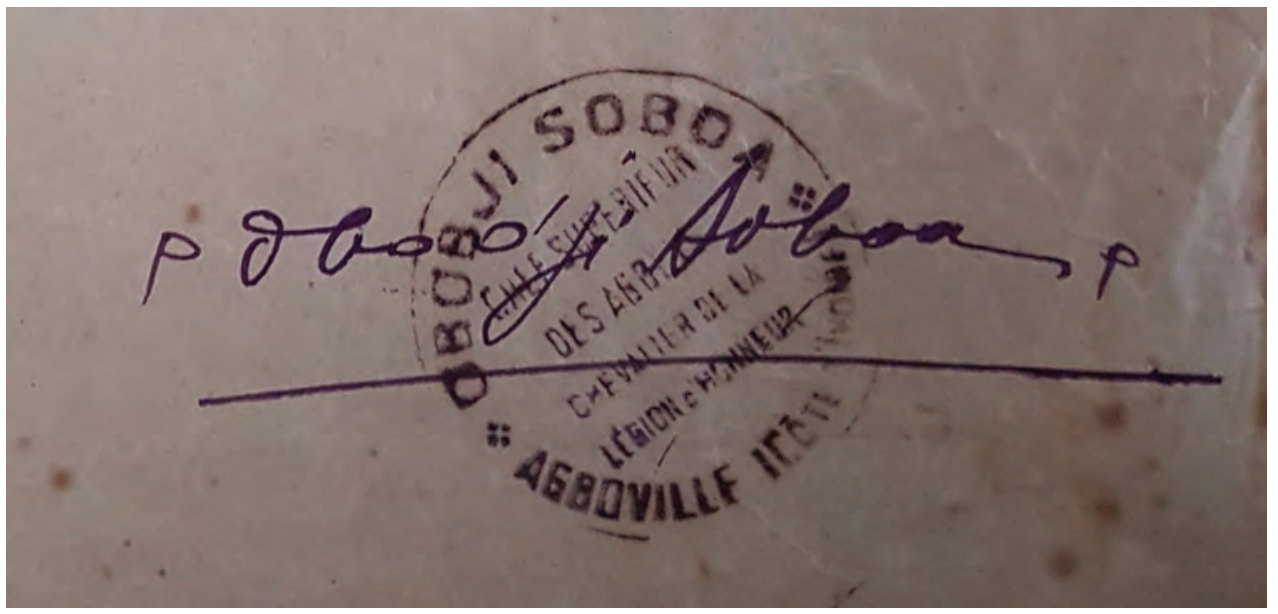

Sceau et signature sur une lettre d'Obodji Soboa au commandant de cercle de l'Agnéby. Obodji parlait bien le français mais n'était pas lettré. La signature sur son sceau, reprise d'un courrier personnel du 29 juillet 1940, est sans doute de son neveu (archives personnelles de Léonard Obodji ; cliché de l'auteur, 2019).

14. Une version peinte en couleur a été postée par Léonard Obodji sur Wikimédia. 


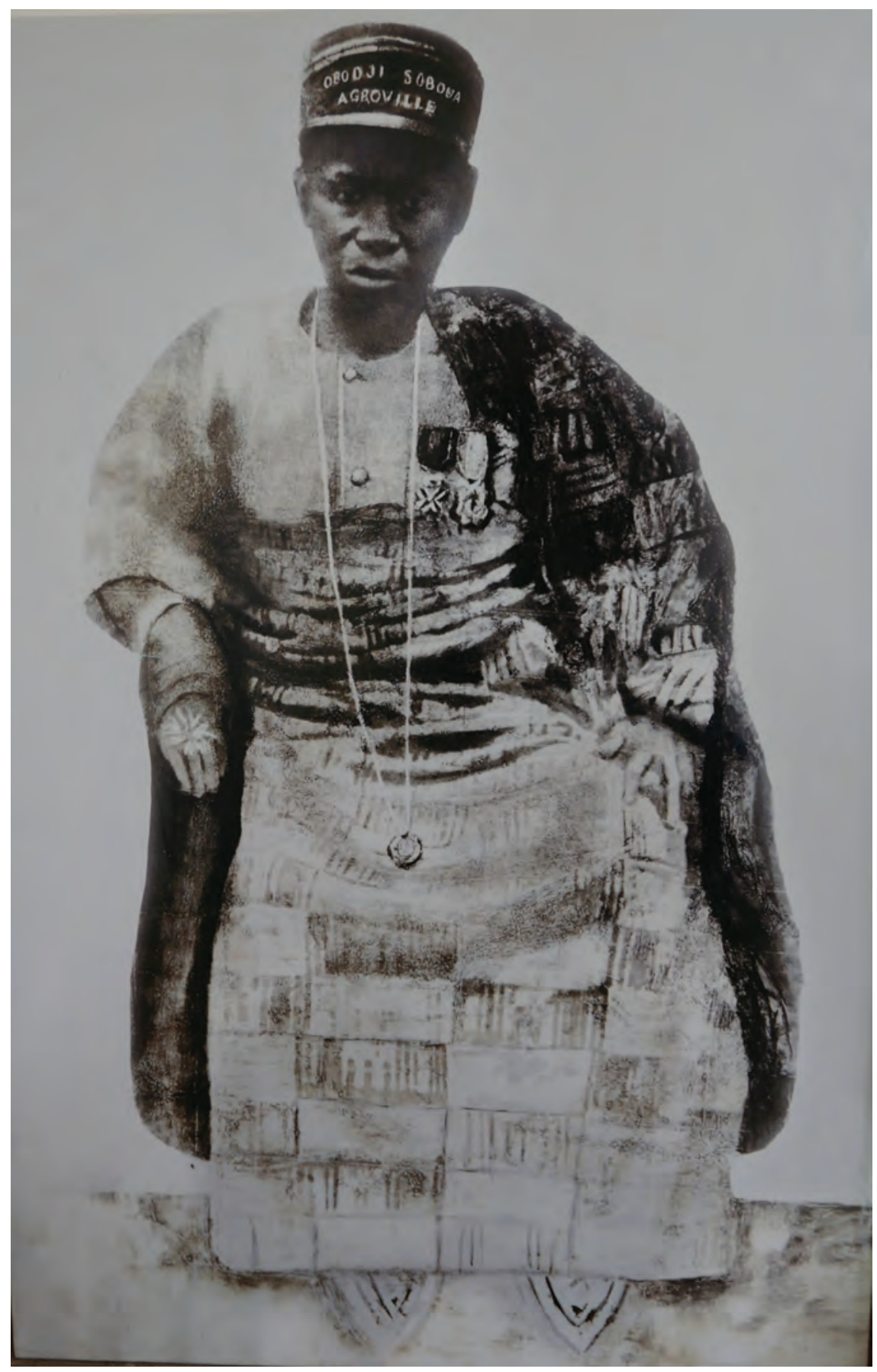

Dans ce portrait en plain-pied d'Obodji Soboa, le chef abbey est vêtu d'un pagne traditionnel rejeté sur l'épaule. "l porte un képi sur lequel est inscrit "Obodji Soboua, Agboville», ses deux décorations françaises et un bijou en or au cou. Quoique l'on ne voie pas d'insignes religieux explicites (à moins que les signes sur la main en soient), ce portrait est saisissant par son enchâssement des registres traditionnels et coloniaux de l'exercice de la puissance (photo prise au tombeau d'Obodji Soboa à Agboville, n.d., cliché de l'auteur, 2019) ${ }^{14}$. 


\section{Très bref historique: les Abbey avant l'arrivée des Français}

La population dite «abbey [abè] » s'est formée au cours des XVIII ${ }^{\mathrm{e}}$ et XIX ${ }^{\mathrm{e}}$ siècles par métissage entre des migrants akan originaires de la zone forestière ashanti et diverses populations usuellement qualifiées d'«autochtones », installées avant eux dans l'actuelle région du fleuve Agnéby. Les mouvements de populations entre cette région et la zone côtière et lagunaire à une centaine de kilomètres plus au sud ont été fréquents dans les deux sens. De ces contacts parfois violents sont restées des influences interculturelles entre Abbey et populations dites «abidji » (installées autour de l'actuelle ville de Sikensi), «adjoukrou » (Dabou), « ébrié » (Abidjan) et «éotilé [bétibé]»(Adiaké). Les historiens insistent sur ces brassages continus, constitutifs de l'ethnogénèse abbey. Comme les autres groupes dits «akan » méridionaux et d'autres populations ivoiriennes, les Abbey n'ont pas une origine commune mais un parcours historique en commun. Leur différentiation s'est construite après leur sédentarisation $^{15}$. Les Abbey sont une société akan dont la spécificité est d'être lignagère et patrilinéaire. Ils se reconnaissent en quatre sous-groupes, sans doute issus de chefs de clans : Abévé, Kho [Ko], Morié et Tioffo [Tchofo] (par la suite érigés en cantons). Le lignage d'Obodji Soboa est Abévé, son village est Loviguié, au sud-ouest d'Agboville.

\section{Histoire du lignage d'Obodji Soboa selon la tradition orale abévé ${ }^{16}$. Selon} les traditionnistes consultés par Georges Niangoran-Bouah, Okouchi ${ }^{17}$ fut le grand ancêtre des Abbey au temps de leur migration à Morié. À sa mort, son fils Ossohougbo - le « grand Ossohou » - prit sa relève et s'installa à Loviguié. Il fut « le véritable organisateur du pays abbey d'Agboville. Ossohougbo dirigea

15. Gonnin et Allou (2006, p. 99-102) ; Ekanza (2006, p. 46-49). Ekanza estime que les Abbey sont encore plus métissés que leurs voisins les Attié [Akyé]. Le melting-pot de la région d'Agboville - selon ses termes - est renforcé par la présence des populations dites "krobou » et " ega ", issues de métissages avec une autre migration venue de l'actuel Ghana. Lors d'une conférence débat sur « Le peuplement abbey et ses origines » donnée à la salle des fêtes d'Agboville le 21 juillet 1984, Niangoran-Bouah affirmait : "Une ethnie, c'est quoi même? Un ensemble d'individus que rapproche un certain nombre d'éléments de civilisation. [...] II n'y a jamais eu dans le monde en Afrique ou en Côte d'Ivoire d'ethnie pure. Une ethnie pure est une vue de l'esprit » (cassette audio de 120 minutes, archives Léonard Obodji).
16. Informations reprises pour l'essentiel du document de synthèse de Niangoran-Bouah (1987), de sa conférence-débat de 1984 sur «Le peuplement abbey et ses origines », d'un entretien avec Augustin Apété, 27 juillet 2019, Agboville, et de discussions au long cours avec Léonard Obodji, Paris et Agboville, février-octobre 2019. Ce récit historique des Abbey fait assurément la part belle au sous-groupe abévé. Le récit narré par François

M'Bassidjé, originaire du canton tioffo (successeur d'Obodji Soboa, voir ci-après), à Claude Pairault en 1966, en diffère sensiblement (Pairault, 1971). La famille Obodji rapporte aussi que Niangoran-Bouah (1935-2002) et Barthélémy Kotchy (1934-2019), son collègue universitaire à Abidjan originaire du canton morié, étaient en désaccord sur divers points de l'histoire abbey. De même, la famille Obodji conteste la version rapportée par Yapi Doffou (2017), qu'elle juge mal informée et dépréciative à l'endroit d'Obodji Soboa.

17. Il est possible qu'Okouchi soit le Kotchi Gbô - "grand chef » en langue abbey - dont Gonnin et Allou datent la migration de l'actuel Ghana à 1721 (2006, p. 100).

18. Toutes citations de cette section reprises du document de synthèse de Niangoran-Bouah. Selon M'Bassidjé, «Ossougbeu commandait les Abévé, Bokagbeu commandait les Morié, Edikedi, ainsi qu'Edike et son frère Bourguimon, ont commandé Tiofo, Asa commandait Kho ": M'Bassidjé était de la cinquième génération des fils d'Edikedi, et petit-fils du chef de Grand-Yapo à l'arrivée des Français. M'Bassidjé rapporte encore que la fête des ignames était célébrée d'abord par les Morié, puis les Tioffo, Kho et Abévé (Pairault, 1971, p. 64-65). 


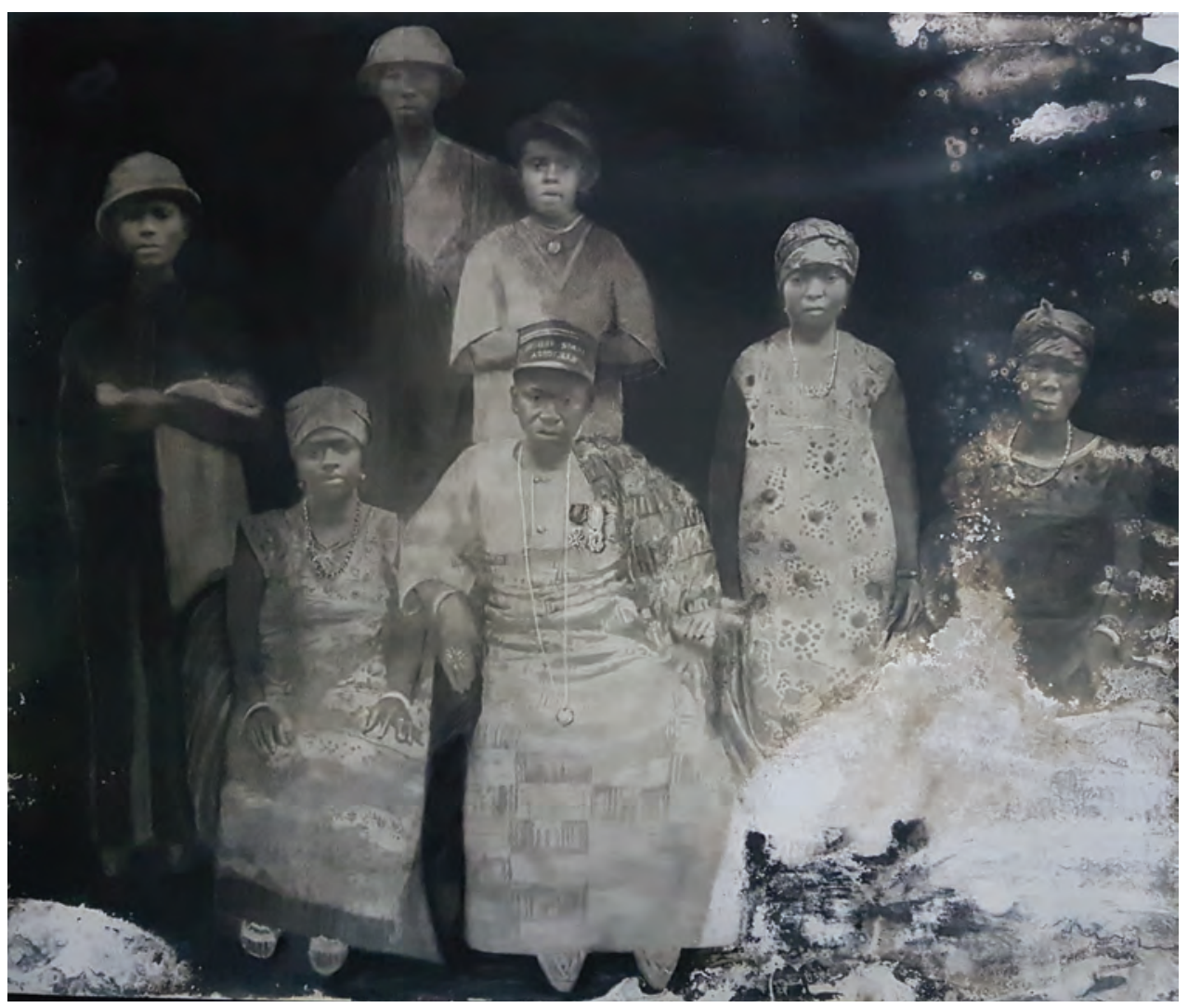

Obodji Soboa et sa famille à Agboville. La même photo se retrouve sur ce portrait de famille (collage ?), datant probablement des années 1930, sur laquelle le chef abbey, son épouse, sa sœur, ses enfants et un autre membre de sa famille sont tous somptueusement vêtus, selon les codes africains et européens (archives personnelles de Léonard Obodji, n.d.

des guerres de conquête contre les voisins pour fixer définitivement les limites frontalières à l'est avec les Akyé (Attié) et à l'ouest sur le fleuve Bandama avec les Baoulé ». Après avoir mené ces guerres de conquête et «soumis les autochtones (douda, abidji, nkoukoudjé et moutcho)» par la force, le groupe abbey mit sur pied « une sorte de confédération avec un chef supérieur spirituel qui devait être assuré par Morié et Loviguié à tour de rôle». Les « dignitaires abbey de toutes les provinces du pays » choisirent Ossohougbo comme chef spirituel et «juge suprême en cas de conflit entre cantons ». Le «jugement de ce dernier [était] sans appel et ne concernait que les problèmes graves susceptibles de diviser le pays ». En temps ordinaire, chaque village - chef de terre, chef de lignage - gérait ses propres affaires : le pays abbey était décentralisé. Ossohougbo « était bon chef de guerre, beau parleur, grand de taille, teint clair, bel homme, juste, pondéré et surtout très riche en poudre d'or (la légende parle de cinq jarres) $)^{18} »$. 
À sa mort lui succéda son fils Ntakpé Soboa - de teboa en langue ébrié, signifiant «beau et propre comme une pagaie »; sa mère s'appelait Edichi. Ntakpé Soboa eut plusieurs enfants dont Obodji, né vers 1886 (ou 1875) ${ }^{19}$ et Meney. C'est à son époque que les Français pénétrèrent dans le pays.

\section{Pénétration coloniale et résistance abbey : d'une révolte à l'autre (1905-1910)}

La révolte de 1905-1906 et la houlette de Ntakpé Soboa. Les Français ont fondé la colonie de la Côte d'Ivoire en 1893, mais le pays abbey ne fut guère investi avant 1903 quand des missions d'études parcoururent la région, l'une pour y déterminer le tracé d'un chemin de fer partant d'Abidjan, l'autre pour y construire un poste à Éry-Macouguié, doté d'un chef de poste, de gardes de police, puis d'un tribunal indigène (le poste fut transféré à Agboville en $1909)^{20}$. Le début des travaux de la voie ferrée en 1905 engendra toujours plus de réquisitions et la venue de nombreux étrangers dont la présence s’installait dans la durée.

À mesure que l'ordre ancien paraissait déstabilisé, Ntakpé Soboa, chef du village de Loviguié, fédéra toujours plus de mécontents, principalement dans les villages abévé et tioffo ; les Morié semblent s'être tenus à l'écart. Les traditionnistes abbey ont raconté à Georges Niangoran-Bouah que Ntakpé Soboa «était contre l'installation des Blancs à Agboville car il trouvait les Français trop exigeants, pas sincères, qu'ils ne tenaient jamais leurs promesses. Pour s'opposer à eux, il pratiquait la politique de la terre brûlée. Il demandait à tous les Abbey et à tous les chefs d'affamer les Blancs et les militaires en cachant les animaux en forêt ainsi que les vivres (ignames, bananes et taros). Pour faire efficacement ce travail, il avait organisé une milice bien armée et bien entraînée ». Des villageois prirent la brousse après avoir envoyé femmes, enfants et bétail en sécurité chez leurs alliés abidji. Il y eut des sabotages et des menaces musclées contre le personnel de la mission d'études du chemin de fer. Un rapport administratif de 1906 vilipendait Ntakpé Soboa : « C'est un personnage de triste réputation. Il vole et rançonne les villageois de son groupe, moyennant quoi, il est très riche et de ce fait très respecté et redouté. » « Dans cette campagne, il est aidé par les féticheurs qui craignent aussi que leur règne ne s'achève, puisque les Européens interdisent les sacrifices et détruisent leurs

19. La date de 1886 figure sur la "Carte de la société d'entraide des membres de la Légion d'honneur » d'Obodji Soboa, datée de 1945 (archives de Léonard Obodji) et sur sa tombe à Agboville. La date de 1875 figure dans le document de synthèse de Niangoran-Bouah. La mère d'Obodji Soboa s'appelait Akouwa.
20. L'administrateur Grivot rapporte qu'Agboville (qu'atteignit la voie ferrée dès 1906) était

" essentiellement une agglomération artificielle [...] créée par les

Européens sans préexistence d'une agglomération africaine

coutumière ». II notait encore en 1955 qu'« Agboville a d'ailleurs conservé ce caractère de ville artificielle en ce sens que la population autochtone, les Abbey, y est en minorité. $84 \%$ des habitants sont de race différente de ceux du cercle dont Agboville est le chef-lieu ». Toujours en 1955, Grivot notait : " Les archives du Cercle sont très pauvres » (Grivot, 1955, p. 84-85). 


\section{Le pays abbey et ses quatre cantons : Abévé, Kho, Morié et Tioffo}

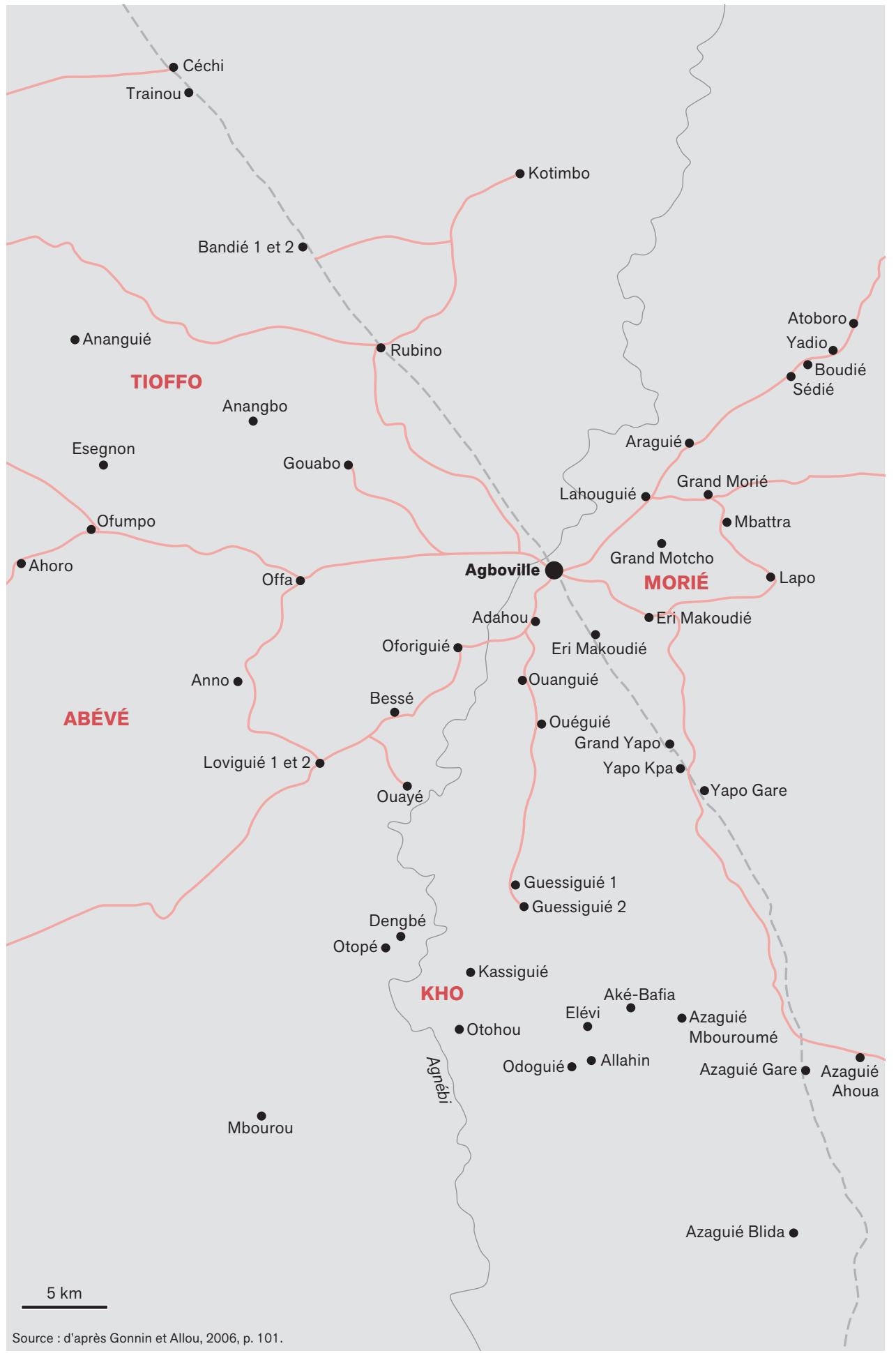


fétiches ${ }^{21}$. » Une épidémie de variole débuta en novembre 1905, qui fut présentée par les rebelles comme une punition des dieux et redoubla la mobilisation villageoise.

Ntakpé Soboa prit la brousse. Dénoncé, il fut finalement arrêté à Gbandjé aux funérailles de son beau-frère ${ }^{22}$. Il fut emprisonné à Agboville puis à Bingerville et après deux tentatives d'évasion manquées, déporté à Tabou à la frontière libérienne en 1906 pour deux ans. Obodji Soboa et son frère Meney proposèrent leur médiation entre les villageois et l'administration pour apaiser la situation. Le calme fut temporairement restauré dans la région.

\section{Le ralliement de Ntakpé Soboa aux Français et la grande révolte abbey}

de 1910. Ces revers provoquèrent chez Soboa-père un complet renversement de position. Les traditionnistes racontèrent à Niangoran-Bouah qu'à Tabou « les Français avaient organisé en présence des résistants noirs prisonniers plusieurs démonstrations de leur puissance militaire ». Ntakpé Soboa se convainquit de la supériorité militaire française et de l'impuissance des Abbey à renverser l'ordre colonial par la violence ${ }^{23}$. Par pragmatisme, il choisit alors la voie de l'accommodement déjà suivie par ses fils. Par leur pression auprès de l'administration, Soboa-père fut transféré en résidence surveillée à Adzopé, en pays attié. Là, « il reçut secrètement plusieurs émissaires abbey. Il leur conseilla de ne pas faire la guerre aux Français mais de négocier. [...] Il connaissait les forces des deux camps en présence. Il savait que les Abbey n'étaient pas bien préparés, n'avaient pas suffisamment de vivres pour soutenir une guerre longue; n'étaient pas suffisamment armés par comparaison à la puissance de feu de la force militaire de colonisation française, la situation enclavée des Abbey entourés par les Français (Bassam-Dabou-Abengourou-Dimbokro, etc.) ${ }^{24} \gg$. Les meneurs abbey issus notamment des lignages morié, qui fomentaient une nouvelle révolte

21. Archives nationales de Côte d'Ivoire (ANCI), 1EE21(1), rapports trimestriels du poste d'Éry-

Macouguié, janvier 1906 - cité dans Guiral (1976, p. 21-22). La note, négative, en partie contradictoire (personnage voleur, de triste réputation vs personnage respecté), traduit surtout le ressentiment colonial.

22. Niangoran-Bouah (1987) La famille Obodji juge Yapi Doffou (2017, p. 34-35) mal informé qui attribue cette peine de prison à un crime passionnel que Ntakpé Soboa aurait commis contre un garde-cercle du commandant, lequel aurait mis sa fiancée enceinte.

23. Enregistrement audio d'un entretien mené en français par Georges Niangoran-Bouah avec un notable abbey, Dechi Orso Pasteur (dit « Dechi Pasteur»), le 10 juin 1978 (archives de Léonard Obodji).

24. Niangoran-Bouah (1987).

25. Voir par exemple Loucou (2007) et Viti (2016).

26. Enregistrement audio d'un entretien mené par Niangoran-Bouah avec Dechi Orso Pasteur le 10 juin 1978.

27. Archives nationales du Sénégal (ANS), lettre du lieutenantgouverneur de la Côte d'Ivoire au gouverneur général de l'AOF, 24 janvier 1910. Obodji Soboa guida la colonne commandée par le lieutenant Boudet, la première à atteindre Agboville (Grivot, 1955, p. 85). M'Bassidjé détaille son itinéraire (Pairault, 1971, p. 66).
28. Par exemple Amos Djoro (1992, p. 456) et Barthélémy Kotchy, de lignage morié.

29. Niangoran-Bouah (1987). La plume emphatique de Yapi Doffou parle de la capture de la panthère vivante comme d'une "bravoure rocambolesque ", «ruse prodigieuse » et «prouesse héroïque » de Ntakpé Soboa. "Les colons trouvés sur place à Agboville [...] trouvaient l'homme providentiel, beau et imposant, ayant naturellement la stature de chef » (2017, p. 35-36).

30. Photocopie partielle d'un rapport trouvé dans les archives collectées par Niangoran-Bouah à Dakar en 1983. 
anticoloniale, ne l'entendirent pas de cette oreille. Ntakpé Soboa fut libéré en 1908 au terme de sa peine. Cette année-là, une note administrative déplorait son assassinat par des « rebelles » abbey, ensuite démenti.

C'est ainsi que Ntakpé Soboa, leader de la révolte de 1905, se désolidarisa de la grande révolte abbey de janvier 1910, qui s'étendit chez les Attié et certains clans baoulé pendant plusieurs mois. Cette grande révolte, lancée par l'attaque d'un train et associée à l'acharnement sur le corps du colon Rubino (qui donna son nom à la ville où il est enterré), au massacre de nombreux colporteurs dioula et d'autres travailleurs étrangers, ainsi qu'à la répression violente de la colonne Noguès, est un épisode bien connu de l'histoire des résistances africaines à la colonisation française en Côte d'Ivoire ${ }^{25}$. Par crainte de représailles de la part des résistants abbey - comme le raconte un traditionniste à Niangoran-Bouah ${ }^{26}$ - ou par mesure préventive, Ntakpé Soboa dépêcha ses fils Obodji et Meney auprès du gouverneur à Bingerville pour rallier les troupes Noguès qui pacifièrent la région. Une note administrative confirme qu'ils leur «serv[irent] notamment de guides ${ }^{27}$ ». D'aucuns y virent une trahison ${ }^{28}$.

\section{Réorganisation coloniale de la chefferie abbey}

En signe de reconnaissance et pour servir ses propres intérêts, l'État colonial nomma Ntakpé Soboa chef des Abbey en 1911. La tradition orale rapporte à ce sujet une anecdote, en forme de parabole, qui éclaire la représentation encore confuse que se faisaient les Abbey de la transition ou du chevauchement alors en train de se jouer entre, d'une part, la puissance du chef dans sa conception locale africaine et, d'autre part, son autorité bornée, adoubée administrativement, selon la conception exogène française. Alors qu'il était encore prisonnier à Adzopé, Ntakpé Soboa « captura une panthère qui venait les nuits prendre le bétail du commandant. Cet exploit fut décisif pour lui rendre sa liberté. Le commandant avait dit à Soboa "si tu as pu prendre une panthère vivante, c'est que tu es encore assez fort, intelligent et rusé pour commander. De ce fait, nous allons accepter la proposition des Abbeys qui font des démarches pour t'avoir comme chef". C'est en présence de tous les Abbeys réunis que le chef suprême des combattants abbeys Gbale Ahou l'a fait reconnaître comme chef suprême des Abbeys. C'est fort de cela que les Français l'avaient nommé en 1911 chef supérieur de tous les Abbeys d'Agboville. Sans sa sagesse et sa clairvoyance, le riche Agnéby aurait été totalement rasé et les habitants tués et éparpillées aux quatre coins de la Côte d'Ivoire ${ }^{29}$ ».

Ntakpé Soboa est mort en 1921. Un rapport administratif le dépeint comme un chef docile : « Soboa, le chef des Abbeys, avait vu la révolte de 1910, il avait assisté à la répression sévère qui suivit, il s'était franchement soumis et c'était un de nos meilleurs chefs; il fut un auxiliaire loyal pour nous ${ }^{30}{ }$. Le contraste avec l'avis très défavorable émis en 1906 est éloquent... Ancré dans la religion traditionnelle, le chef abbey ne semble pas s'être interposé face à la répression coloniale contre les communautés harristes de la région d’Agboville 
en février $1915^{31}$. (Ces communautés survécurent : en 1924, des émissaires abbey représentant environ quatre-vingt églises locales se rendirent en BasseCôte pour y croiser des missionnaires méthodistes européens, qui, débordés, ne purent leur envoyer de prédicateur ${ }^{32}$ ). La tenure de fonction du vieux Soboa apparaît sans histoire.

Obodji Soboa succéda à son père le 27 avril $1923^{33}$. Si Soboa père, âgé et non francophone, déjà chef avant la colonisation, fut un chef d'un genre encore traditionnel, Obodji Soboa devint un chef supérieur d'un genre nouveau, d'une tout autre envergure. Le pays abbey était traditionnellement décentralisé et les différents chefs de villages n'étaient pas spontanément enclins à soutenir l'autorité suprême du jeune chef imposé par les Français. Pour nouer un pacte de confiance réciproque, Obodji Soboa et les chefs abbey passèrent un « fétiche collectif $^{34}$ » ou rituel d'allégeance. Les chefs crachèrent l'un après l'autre dans une sorte de canari servant de pot de chambre, puis le chef Obodji en but le contenu en prêtant serment de ne jamais trahir les intérêts des Abbey ${ }^{35}$. Même si Obodji Soboa concéda par là une déférence ne serait-ce que symbolique à la tradition, des chefs et des notables, en particulier tioffo, continuèrent à nourrir plus ou moins ouvertement une certaine défiance à son endroit, estimant peut-être qu'Obodji servait surtout les intérêts des Français et, par-delà, les siens propres. Assurément, Obodji Soboa fut longtemps perçu comme un grand serviteur de la France. Il fut promu chevalier de l'ordre de l'Étoile d'Anjouan en 1927 et grand officier de l'ordre national de la Légion d'honneur en 1932. Ce satisfecit colonial dura jusque vers 1938.

Il importe de répéter que la lignée d'Obodji Soboa du village de Loviguié du canton abévé n'était pas détentrice d'une autorité coutumière s'exerçant sur l'ensemble des Abbey car cette autorité était historiquement décentralisée. Elle inaugura une nouvelle « chefferie administrative » ou « chefferie de province » en pays abbey, type de «commandement indigène » officialisé par un arrêté territorial le 10 octobre 1934. Le choix d'inscrire géographiquement son siège à Agboville, ville de création européenne sans passé africain, située à équidistance des quatre cantons abbey (voir carte 1), put contribuer à son acceptation par les chefs et la population.

31. En février 1915, un régiment de tirailleurs sénégalais circula en pays abbey pour y détruire les églises harristes et tenter d'éradiquer la «nouvelle religion qui n'était rien d'autre qu'un moyen de s'opposer à notre autorité ", selon le chef de poste d'Agboville.

32. Fonds de la Methodist Missionary Society of French West Africa : lettre du pasteur Wood au pasteur Thompson, 18 novembre 1924 (Haliburton, 1971, p. 182).
33. II n'était pas le premier dans la ligne successorale, mais son frère aîné se désista en reconnaissant sa meilleure maîtrise du français et son charisme (entretien avec Léonard Obodji, Paris, 26 février 2019). La date de 1923 figure dans NiangoranBouah (1987).

34. L'expression est de Yapi Doffou (2017, p. 38).

35. Entretien avec Augustin Apété, 27 juillet 2019, Agboville. Récipient d'urine, crachats à boire : par ces fluides peu nobles, le rituel place le chef suprême en position d'infériorité vis-à-vis de ceux amenés à être ses subordonnés. Traditionnellement, la trahison d'un serment de ce type est la mort.

36. Amos Djoro (1992, p. 458). Il existe une abondante littérature sur le prophète Harris. Voir par exemple Haliburton (1971), Shank (1994), Dozon (1995), Bureau (1996). 


\section{Document. La chefferie administrative, une invention coloniale (extraits repris d'Amon d'Aby [1958, p. 25-26])}

Le nouveau chef indigène issu de la conquête diffère totalement du chef traditionnel d'hier. Cette distinction est essentielle, et les grands maîtres de la doctrine politique coloniale l'ont précisée avec netteté afin qu'il ne subsiste aucune équivoque dans les esprits sur cette importante question. Voici ce qu'en dit [le gouverneur-général de l'AOF] Van Vollenhoven : «Les chefs ne sont pas d'anciens souverains dont nous voulons ménager les trônes; les trônes ou bien n'existaient pas, ou bien ont été renversés par nous et ne seront plus relevés. Entre nous et les populations, il doit y avoir un truchement : c'est le chef qui est le truchement; non parce qu'il nous est imposé mais parce que nous l'avons choisi [...]. »

Après Van Vollenhoven, l'inspecteur Maret s'est attaché surtout à définir ce qu'est le chef de canton, et ce qu'il n'est pas, ainsi que sa place dans la hiérarchie administrative.

«Que l'on s'entende bien sur les définitions, écrivait-il dans son rapport du 5 décembre 1930, le chef de canton n'est pas le continuateur de l'ancien roitelet indigène, exerçant autrefois une autorité basée sur la coutume ou la violence, et que nous serions venus limiter, tempérer ou contrôler. Même lorsqu'il y a identité de personne, il n'y a plus rien de commun entre l'état de chose ancien et le nouveau. Le chef de canton, fût-il le descendant du roi avec lequel nous avons traité, ne détient aucun pouvoir en propre. Nommé par nous, après un choix en principe discrétionnaire, il est, et il est seulement, notre auxiliaire. Il met à notre service sa connaissance du pays, son influence, son prestige. Et c'est tout. Il ne fait qu'exécuter nos ordres. »

À tout le moins, c'est ce que les colons croyaient... La trajectoire d'Obodji Soboa révèle que la chefferie administrative put donner appui à des initiatives autonomes qui ne servaient pas exclusivement l'agenda colonial.

\section{L'Église d'Aké Offo: Obodji Soboa, quasi-prophète en son pays}

Né avant l'arrivée des Français, Obodji Soboa avait été élevé dans les croyances traditionnelles africaines. Avant de devenir chef à Agboville, il avait longuement séjourné à Dabou puis à Grand-Bassam où il s'était formé aux activités d'exploitant forestier et de commerçant, au service de riches Adjoukrou et N'zima, en côtoyant des Sierra-Léonais, des Sénégalais et d'autres étrangers. Selon Ernest Amos Djoro, ancien ambassadeur ivoirien et auteur d'une thèse inédite sur les mouvements religieux issus de la prédication prophétique du Libérien William Wadé Harris en Côte d'Ivoire en 1913-1914, c'est au cours de ces séjours en Basse-Côte qu'« Obodji Soboa reçut diverses influences religieuses dont le catholicisme et l'islam ${ }^{36}$ ». Il n'est pas attesté qu'il croisât le 
prophète Harris mais il est probable qu'il rencontrât des fidèles, voire des apôtres d'Harris.

L'appel aux missionnaires catholiques, 1926. Devenu chef supérieur des Abbey en 1923, Obodji Soboa introduisit, dans un premier temps, le catholicisme à Agboville. Selon le témoignage de Mgr Jules Moury, alors vicaire apostolique de la Côte d'Ivoire, la station d'Agboville n'était pas à l'époque « au programme » de la Société des missions africaines (SMA) de Lyon, en charge d'évangéliser la colonie. Si elle fut finalement fondée en 1926, ce fut sur invitation expresse d'Obodji Soboa. Mgr Moury expliqua : « Le chef de cette tribu [abbey] nous a fait remettre une somme de 50000 francs pour la construction d'une église et d'une résidence de missionnaires à Agboville ${ }^{37}$. » Cette somme considérable provenait de fonds propres d'Obodji Soboa et de cotisations de « ses peuples [pour] les sommes (par tête) suivantes : homme 3 francs, femme 1,50 franc, enfant 0,50 franc $^{38}$ ». C'est ainsi qu'en novembre 1926, le père Gandon débarqua à Agboville pour s'atteler à la mise en place de la nouvelle station.

Courant 1927, quarante ans après sa grande mission d'exploration, Louis-Gustave Binger, premier gouverneur de la colonie, fit une tournée en Côte d'Ivoire. À Agboville, il rencontra le chef supérieur Obodji Soboa, déjà fort riche (plus de détails ci-après). Il raconta :

«Devant cette abondance de ressources, je lui ai paternellement fait des suggestions : puisqu'il ne dépensait qu'une minime partie de ses revenus, il devait consacrer quelques-unes de ses ressources au bienêtre commun des anciens sujets de son père.

"J'y songe ! me dit-il, car il parle bien le français. Je vais faire construire, dès à présent, une école, et après cela une cathédrale [il voulait dire : une église].

- Je ne te savais pas chrétien.

- Je ne le suis pas encore.

- Pourquoi?

- Parce que j'ai encore quatre femmes et ta religion n'en tolère qu'une.

37. Cité dans Trichet (1995, II, p. 62-63) et confirmé dans le coutumier de la station Saint-JeanMarie-Vianney d'Agboville (1926-59), 18 janvier 1927 (archives de Léonard Obodji ; toutes citations du coutumier tirées de cette source).

38. Amos Djoro (1992, p. 458).

39. Binger (1938, p. 255)

40. Le coutumier de la station d'Agboville (1926-1959), minutieux par ailleurs, ne fait pas état de sa conversion, et la famille d'Obodji Soboa n'en a pas non plus le souvenir (entretien avec Augustin Apété, Agboville, 27 juillet 2019). Mais selon Dechi Orso Pasteur consulté par Niangoran-Bouah, Obodji Soboa était à l'époque un catholique pratiquant, qui allait à la messe « chaque matin et chaque soir » (enregistrement audio du 10 juin 1978).

41. Les prophètes avant Aké en Côte d'Ivoire furent Libériens. Aké était
Alladian, mais les Alladian furent peu nombreux à le suivre : il ne fut pas prophète en son pays (en son territoire d'origine), mais prophète chez ses voisins, en pays akjoukrou. 42. Cité dans Augé (1969, p. 186). 43. De Billy (1931, p. 20-21 et ci-après). Le pasteur de Billy était en poste à Dabou à l'époque. 44. Augé (1969, p. 186). 
- Alors?

- Alors, j'attends! Quand je serai assez vieux pour en avoir une seulement, je me ferai chrétien"39. »

Le 6 juin 1927, après cinq mois de travaux, l'église Saint-Jean-MarieVianney d'Agboville était inaugurée en grande pompe, en présence du vicaire apostolique. Le coutumier de la station missionnaire rapporte : « [L]e chef du pays, Obodji Soboa, grâce à la générosité duquel la mission a été construite si bien et si rapidement, a aujourd'hui sa récompense : il a sa place d'honneur dans le chœur, seul en face de monseigneur » Moury. Obodji Soboa s'était-il donc converti au catholicisme ? Rien n'est moins sûr ${ }^{40}$. Il est clair à tout le moins qu'Obodji Soboa appuyait à l'époque, par ses ressources politiques et économiques, la diffusion de la religion et de l'éducation catholiques en pays abbey. De fait, Obodji Soboa est considéré comme le promoteur de la première école (formelle, de langue française) en pays abbey. En 1927, il était l'un des rares chefs ivoiriens, avec Boa Kouassi de l'Indénié, à envoyer son fils, Emmanuel Indikeu Soboa, baptisé catholique, étudier le droit en France.

Mais le ralliement d'Obodji Soboa à la religion des pères SMA fut de courte durée. Selon le traditionniste enregistré par Niangoran-Bouah, ce sont les incartades sexuelles répétées d'un père SMA avec plusieurs femmes mariées d’Agboville qui précipitèrent la rupture.

L'influence du prophète Bodjui Aké, 1929. Vers 1929, Obodji Soboa entendit parler de Bodjui Aké, nouveau prophète à Dabou ; il s'y rendit le rencontrer. Apparu en 1926, Bodjui Aké a été le premier prophète ivoirien à faire émerger une Église nouvelle, inspirée d'Harris, dite « religion Aké » ou « akéiste », farouchement hostile aux missions méthodistes wesleyennes qui revendiquaient aussi l'héritage d'Harris ${ }^{41}$.

On sait peu de choses sur la religion Aké, qui n'eut peut-être pas le temps de se structurer du vivant du prophète. Le gouverneur Lapalud rapporte qu'Aké «baptise avec l'eau du ciel et enseigne une sorte de protestantisme sommaire adapté aux compréhensions simplistes des indigènes ${ }^{42}$ ». Imitateur d'Harris, Bodjui Aké était illettré et faisait peu usage de la Bible. Pour le missionnaire méthodiste Edmond de Billy, Aké n'incarnait rien moins qu'un réveil du « passé païen », rebelle à « la religion des Blancs de l'Évangile, jugée par beaucoup, à l'usage, trop difficile et trop exigeante ${ }^{43}$. L'anthropologue Marc Augé considère la religion Aké comme un «culte anti-“fétiches" et anti-“sorcier"44 », sans plus de précision - mais en cela, elle ne différait pas du prophétisme d'Harris (et des autres prophétismes africains). Dozon pense qu'à l'instar d'Harris, Aké n'était pas défavorable à la polygamie.

Contrairement à Dô - un autre prophète d'origine libérienne qui l'avait précédé en Basse-Côte et rallia surtout des jeunes -, Bodjui Aké fut soutenu, selon de Billy, par des «partisans âgés de plus de 50 ans ». Selon Amos Djoro, « [c]'est ainsi que la communauté Adjoukrou [des alentours de Dabou] se scinda 
en deux groupes correspondant aux “classes d’âge ou générations”. Le groupe des anciens et des chefs [partisans d'Aké] qui avaient entendu le message de Harris de la bouche même du prophète et qui manifestaient d'autant plus d'animosité à l'égard de la Mission [protestante] qu'elle lésait leurs intérêts en favorisant l'essor des jeunes. Celui des benjamins qui, groupés autour des catéchistes et des prédicateurs [méthodistes, adversaires d'Aké], osaient pour la première fois tenir tête au nom de la religion à cette gérontocratie qui, traditionnellement, se réservait les jeunes filles et les produits de la vente de l'huile de palme ${ }^{45}$ ».

La prédication d'Aké provoqua des conflits et des divisions villageoises, sauf à Lopou où toute la population, suivant leurs chefs, devint partisane d'Aké. Lapalud rapporte que «[d]ans quelques villages on se dispute la propriété des temples élevés autrefois à frais communs, des bagarres s'en suivent quelquefois ${ }^{46}$ ». L'usage des temples fut parfois partagé à mi-temps ; ailleurs de nouveaux temples furent construits. C'est ainsi que de nombreux villages adjoukrou avaient désormais trois ou quatre églises : catholique, méthodiste, harriste et akéiste... L'administration fut d'abord encline à laisser le champ libre à Aké contre les protestants, perçus comme des adversaires anglophiles. Elle intervint ensuite pour préserver l'ordre public : obligation d'horaires décalés pour les cultes akéiste et méthodiste, déposition de quelques chefs, etc.

C'est ce prophétisme conservateur d'Aké, dont le trait le plus original fut de s'attirer les bonnes grâces des anciens et des chefs, qui attira la sympathie du chef Obodji Soboa, donnant naissance à un tout premier «lignage prophétique » ivoirien. Obodji Soboa adopta son culte vers 1929 et commença à le diffuser dans sa province, où il fut connu comme "religion d'Aké Offo » ou « religion du Dieu d'Akè », en langue abbey. Deux mois avant la mort du prophète fondateur en 1931 (ou 1932), Bodjui Aké fit à son tour le déplacement à Agboville pour y baptiser les Abbey initiés par Obodji Soboa (un malentendu avec le commandant de cercle fit qu'Aké ne put baptiser les fidèles qu'à Loviguié, village d'origine des Soboa $)^{47}$. Le missionnaire méthodiste André Roux résuma d'une plume expéditive : «[L]e chef supérieur des Abbey entend[it] parler de [Bodjui Aké] et de son autorité dans la région côtière. Il a vu ce que signifie, plus au nord, en pays musulman, la réunion des pouvoirs temporel et spirituel en une seule main, et a décidé d'en tirer leçon. Il appelle donc Aké, le charge d'organiser son culte en pays abbey, se fait instruire lui-même, puis, le citron pressé, il jette l'écorce et s'institue chef religieux de cette tribu dont il est déjà le chef politique. » «En fait, sous le pavillon du harrisme, un culte a été établi par un chef astucieux comme l'élément intégrant qui assurera son pouvoir dans la communauté nouvelle qu'il a conçue ${ }^{48}$. »

45. Ibid., p. 447.

46. Cité dans Augé (1969, p. 186).

47. Enregistrement audio d'une conversation entre Niangoran-Bouah et un prédicateur de la religion

Obodji-Aké à Laouguié (dont le nom n'est pas précisé), en langue abbey, traduction par Léonard Obodji, n.d. 48. Roux (1971, p. 44). Le pasteur Roux séjourna en Côte d'Ivoire de 1937 à 1945.

49. Ibid., p. 175-176.
50. Amos Djoro (1992, p. 459). 51. Chivas-Baron (1939, p. 172); mentionnée dans Dozon (1995, p. 83). 
Rupture avec la mission catholique, 1930. En janvier 1930, le coutumier de la station d'Agboville confirmait laconiquement les faits : « À noter qu'Obodji quitte l'Église pour établir à Agboville la religion dite "Aké". Il entraîne à sa suite bon nombre de catéchumènes. » En janvier 1931, un frère d'Obodji Soboa resté catholique eut droit à des funérailles chrétiennes. Le coutumier rapporta : «Pour la circonstance, Obodji qui n'avait plus mis les pieds à l'église depuis un an, assista à la messe avec tous les principaux des Abbeys, la plupart comme lui pratiquants de la religion Aké » - ce qui souligne que les chefs et les notables, comme en pays adjoukrou, appuyaient la nouvelle religion. Entre Obodji Soboa et les catholiques, les tensions s'envenimèrent ensuite dans plusieurs localités. Le coutumier notait, en septembre 1933 : «À Loviguié [village d'origine des Soboa], les Aké installent leur temple à vingt mètres devant l'église [...]. Tout ce mois est marqué par une série de palabres dans ce village entre catholiques et Aké. Le fils du chef de tribu et en même temps chef Aké, le jeune Dobra, élève de l'école régionale, est empoisonné par sa famille parce qu'il ne veut pas suivre la religion de son père. Après aussi avoir le baptême [sic] contre le gré de sa famille, il meurt dans son village d'origine à Loviguié, martyre de sa foi. Ce même mois et dans le même village de Loviguié, les Aké rentrent dans l'église catholique du village et pillent tout ce qui s'y trouve. Intervention de l'administration et sanctions. » Deux mois plus tard, le village d'Ananguié «a eu son église également pillée par les partisans d'Obodji Soboa, chef de tribu des Aké ». Le mois qui suivit, « les Aké mirent le feu » à l'église de M’Bérié ; l'affaire fut confiée à l'administration ${ }^{49}$. En janvier 1934 à Akoupé, « les Aké troublent les cérémonies » de baptême catholique «par leurs chants et leurs danses ». Si Bodjui Aké en Basse-Côte avait concurrencé les méthodistes dont il était issu, Obodji Soboa pour sa part concurrençait les catholiques dont il avait été proche...

Un prophétisme « officiel » en pays abbey. Selon Amos Djoro, le culte Aké d'Obodji Soboa «fut imposé à tous les peuples abbey sous peine d'amende ou d'emprisonnement ${ }^{50}$ » et des chapelles élevées dans les cinquante-deux villages abbey. Le pasteur Roux fait mention de menaces voilées au poison contre les chefs de village accueillant des missionnaires catholiques ou protestants. Bien que de nombreux Abbey fussent restés fidèles aux religions traditionnelles et que la vie catholique continuât de se développer lentement, l'Église d'Aké $O f f o$ s'efforçait, semble-t-il, d'imposer une sorte de théocratie à l'échelle de la chefferie de province.

Obodji Soboa reprit des éléments du culte harriste-akéiste mais introduisit des innovations qui n'étaient pas banales. Selon diverses sources externes, la communauté avait trois ou quatre jours chômés. Selon la voyageuse française Clothilde Chivas-Baron, témoin oculaire en 1933 : « [C] ] haque dimanche, un office avec simulacre de communion, avec méditation et chœurs alternés, avec prières et danses, édifie et réjouit les fidèles que la fatigue n'accable pas ${ }^{51}$. » Obodji Soboa était seul habilité à donner la communion (sans 
confession), avec du pain et du «Berger 45 », un pastis importé. « Le rite interdit la viande de poulet, de singe, la banane pilée ${ }^{52}$. $\gg$ Des cultes avaient lieu quotidiennement et les fidèles devaient porter un costume de couleur différente selon le jour de la semaine, blanc avec une croix rouge, rouge avec une croix blanche, ou noir. Obodji s'était fait commerçant pour assurer la vente du pastis, croix, bonnets et costumes. Obligation était faite aux fidèles de faire leur toilette avant les repas et chaque dimanche. Les hommes avaient la responsabilité de prier pour le salut des femmes, des jeunes garçons et des enfants, considérés comme mineurs devant Dieu. Il est probable qu'Obodji fut tolérant envers la polygamie. Amos Djoro vit dans ces éléments une influence islamique. Ces aspects témoignent à tout le moins d'une vigoureuse idéologie patriarcale.

Nouveau pèlerinage et autres innovations prophétiques. La plus grande innovation religieuse d'Obodji Soboa a été son pèlerinage annuel, qui avait pour théâtre l'une de ses plantations près du village de Babiahan. Amos Djoro écrit : «Dans sa plantation se dresse une colline qu'[Obodji] a baptisée Jérusalem et qui servait de lieu de purification pour ses fidèles. On y allait tous les ans en cortège pour des cérémonies solennelles. Chaque membre emportait mouton, canard, poulet ou argent destinés au sacrifice et à la communion. On dansait et on passait la nuit en plein air. Le troisième jour, le "prophète" montait sur la colline pour recevoir le message de la part de Dieu tandis que les "chrétiens" l'attendaient au pied de celle-ci. Un moment plus tard, il redescendait du "lieu saint" avec un air extasié et ordonnait par des gestes de la tête et des mains la fin de la cérémonie et le départ immédiat des fidèles qui devaient s'enfuir en abandonnant les animaux non sacrifiés. "Dieu enverrait ses anges les prendre.” Et malheur à celui qui regarderait derrière lui. Il risquait de connaître le même sort que la femme de Loth (histoire de Sodome et Gomorrhe) $)^{53}$. »

Un prédicateur d'Obodji Soboa proposa un autre récit sur la religion d'Aké $O f f o$, plus intime et plus mystique. Ce prédicateur raconta à NiangoranBouah qu'après le passage de Bodjui Aké en pays abbey, puis son décès deux mois après, Obodji Soboa continua à pratiquer cette religion, jusqu'à l'arrivée d'un certain Demba. Demba avait entendu parler du travail spirituel d'Obodji Soboa et lui proposa de lui enseigner la religion. Obodji accepta. Un jour, Demba dut partir mais lui fit savoir qu'il le préviendrait de sa date et de son heure de retour. Il précisa aussi qu'à son retour, Obodji et ses prédicateurs

52. ANS, $2 \mathrm{G} / 33-14$, page 113 d'un rapport partiellement photocopié (sans la page de datation) trouvé dans les archives personnelles de Niangoran-Bouah. Ce rapport mentionne qu'Obodji Soboa appela son culte "Église Christiote» [Christ Church], mais sauf dans
Chivas-Baron (1939), l'appellation n'est confirmée nulle part ailleurs. 53. Amos Djoro (1992, p. 461), d'après le témoignage du «pasteur $B$. Orsot-Dessi » [Dechi Orso Pasteur], étudiant à la faculté protestante de théologie de Paris lors de l'entretien en 1956.
54. Enregistrement audio d'une conversation entre Niangoran-Bouah et un prédicateur de la religion Obodji-Aké à Laouguié, en langue abbey, n.d.

55. Amos Djoro (1992, p. 451). 
devraient être en mesure de continuer le travail spirituel par eux-mêmes. Le prédicateur détailla : «Demba est donc parti. Plus tard, il écrit pour dire qu’il revient tel jour par le train de deux heures. Un peu avant deux heures, Obodji Soboa demande un seau d'eau pour se laver, en l'attendant. Et pendant qu'il se lave, Ekissi Agnan se rend à l'église pour faire sonner la cloche et là, il voit un objet qui brûle [brille ?]. Dès qu'il a fini de faire sonner la cloche, Ekissi Agnan court chez Obodji Soboa et lui raconte ce qu'il a vu. Obodji lui demande de ne pas y toucher. C'est le colis que Dieu lui a envoyé. Demba a annoncé qu'il arrive à deux heures, mais en lieu et place, c'est ce colis que Dieu a envoyé. Obodji se sèche, se drape de blanc et se rend à l'église. Quand il s'approche de l'objet, celui-ci s'éteint. On détache l'objet et on découvre qu'il contient un beau boîtier en argent, qui contient une feuille de papier. Obodji fait appeler toutes les personnes qui pratiquent le mysticisme dans la région d'Agboville. Quand ces voyants [visionnaires ?] n'ont rien eu à dire, il fait appeler Monsôh Andrin, son neveu, qui lui dit: "Dieu t'a envoyé ce colis, c'est pour t'aider à faire ton travail spirituel. Sur le papier, il est écrit : regardez bien dans la boîte, il y a un liquide de Dieu et un talc, il faut travailler avec. L'eau est un puissant médicament que les gens doivent boire, ou se laver avec. Le talc est aussi un médicament, il y en a de trois sortes : rougeâtre, blanc et gris. Si une forêt est réputée maudite ou ensorcelée, on déverse le talc et tous les mauvais génies s'enfuient. Dans le coffret, il y a aussi trois perles blanches [des perles traditionnelles en pierre]. Les dames doivent mettre ces trois perles sur une cordelette et l'attacher autour de leur bassin. Le papier contient encore un dernier message. Il faut qu'Obodji trouve une montagne dans la région, qu'il la fasse désherber et qu'il y bâtisse une église pour les offices du samedi." C'est ainsi qu'Obodji est allé à la recherche d'une montagne et la zone qu'il a choisie est aujourd'hui proche du village de Babiahan, derrière le fleuve ogbo [l’Agnéby]. On y allait pour prier, danser, faire des offrandes et faire la fête. On tuait pas mal de poulets que les fidèles amenaient, et ils étaient nombreux à venir. Obodji Soboa, quant à lui, offrait un mouton ${ }^{54}$. »

Ce récit évoque la prégnance des cultes traditionnels dans la religion d'Akè $O f f o$, qui s'est en partie autonomisée du culte originel d'Aké après la mort de ce dernier. Cette religion était tout à la fois un culte anti-sorcier et un culte de fécondité, pratiquant la transe, la musique et les agapes, loin des enseignements missionnaires et du référent biblique quoiqu'avec de la déférence pour l'écrit médiatisant la parole de Dieu.

La religion d'Aké-Obodji tenait pour partie d'un prophétisme ethnique abbey, Obodji devenant quasi-« prophète en son pays ». Mais cette religion fut aussi diffusée en pays abidji. Les Abidji, vassaux des Adjoukrou, avaient déjà subi l’influence directe du prophétisme de Bodjui Aké, par le sud. Les Abbey étaient alliés des Abidji - Soboa-père avait fait se réfugier chez eux les noncombattants en 1905. Les envoyés d'Obodji poursuivirent l'évangélisation akéiste des Abidji, par le nord : les villages de Sahué, Gomon et Katadji en particulier furent réceptifs à l'influence akéiste d'Obodji ${ }^{55}$. 


\section{L'or jaune et l'or brun : un richissime entrepreneur polyvalent}

Chivas-Baron et Amos Djoro ont relevé que les fidèles payaient un denier du culte et s'approvisionnaient dans les magasins du chef supérieur/chef de culte en tissus, pastis et autres objets rituels, enrichissant le chef Obodji. Cela ne fait aucun doute, mais il faut rappeler que la fortune de ce dernier, considérable, était déjà bien établie avant sa conversion, comme Louis-Gustave Binger y faisait allusion en 1927 (citation ci-avant) : sa richesse ne dépendait pas de ses activités religieuses.

Comme d'autres chefs akan, Obodji Soboa avait une fortune en or - peutêtre en partie héritée de son père et de son grand-père. Augustin Apété rapporte que l'essentiel de la fortune de son grand-oncle fut placé dans une banque qu'il avait lui-même fondée, dénommée «Société de prévoyance sociale », aussi connue sous le nom de «Banque Obodji Soboa ». Les chefs de canton abbey y étaient actionnaires. La banque comptait encore des partenaires américains. « On raconte », écrit Niangoran-Bouah, « qu'en 1927, [1]es avoirs [d'Obodji] en banque s'élevaient à 32000000 de francs, officiellement on parle de revenus annuels de 600000 francs $^{56}$. »

Déjà en 1922, peu après la mort de son père, Obodji Soboa avait créé « une coopérative de construction de maisons qui bâtit le quartier qui porte son nom à Agboville »: Obodjikro. Il «commanda[it] spécialement à la Cie Ichabod T. Williams Esons à New York les tôles nécessaires qu'il distribua[it] aux bénéficiaires gratuitement pour achever leurs maisons ». Sa propre résidence fut construite sur deux niveaux, sur des fondations en pierre, avec un système hydraulique de raccord à un réservoir d'eau adjacent (permettant d'avoir l'eau courante en salle de bain) et une toiture de tuiles en provenance de Marseille. Il acquit aussi un immeuble à Abidjan.

L'une des premières activités rémunératrices d'Obodji Soboa avait été l'exploitation forestière en Basse-Côte, dès avant la première révolte abbey de 1905 que son père avait dirigée (lui-même ne s'y étant pas directement mêlé). Obodji poursuivit ces activités et serait devenu, d'après les témoignages recueillis par Niangoran-Bouah, «l'un des plus grands exploitants forestiers ivoiriens qui avaient des correspondants à New York, à Liverpool et à Hamburg ».

La fin de la Première Guerre mondiale avait refermé la page de la pacification et ouvert l'ère de la pax colonia, synonyme de «mise en valeur » du territoire, principalement par le développement de l'économie de plantation. Obodji Soboa se fit alors planteur. L'administration coloniale rémunérait les chefs supérieurs (et les chefs de canton, selon leur grade) et leur concédait diverses aides et avantages pour les inciter à développer des «plantation[s]

56. Niangoran-Bouah (1987). Hors mention contraire, toutes les informations de cette section sont reprises de cette source.

57. Circulaire de l'administrateur chef Boutonnet au sujet de la réorganisation du commandement indigène, 20 novembre 1930, citée par Grah Mel (2003, p. 188, note 10)

58. Document de synthèse de

Niangoran-Bouah (1987).

59. Il est probable que ces

travailleurs étaient, au moins en

partie, des fidèles du culte d'Aké Offo.
D'autres prophètes à la même époque faisaient aussi travailler leurs fidèles gratuitement sur leurs plantations (mais à une moindre échelle), en échange d'une prise en charge spirituelle et parfois thérapeutique. 


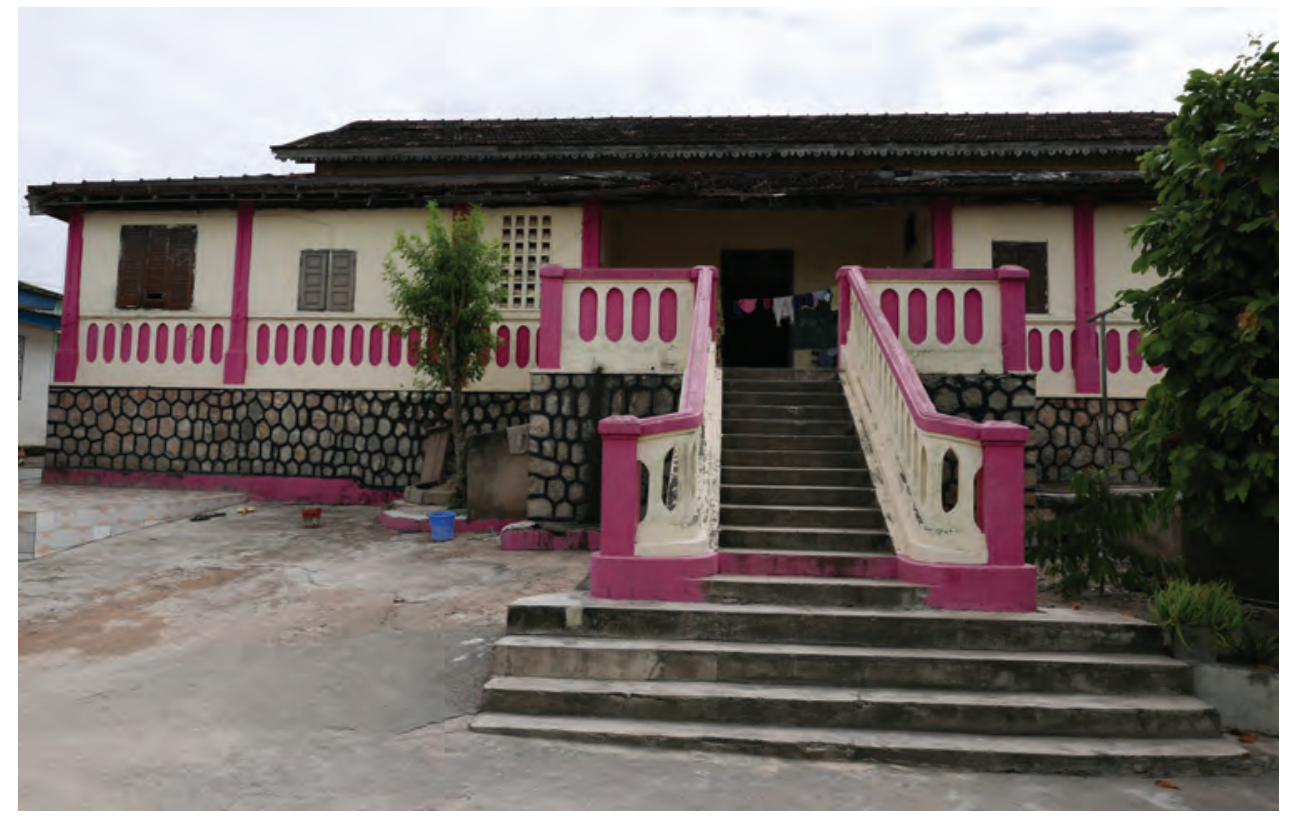

La résidence d'Obodji Soboa, au quartier Obodjikro à Agboville, lui servait aussi de lieu de réception. Elle n'est plus habitée mais est préservée et a relativement bien résisté au temps. En 2019, toutefois, sa toiture était en partie effondrée. Les pièces et quelques éléments du mobilier d'époque, dont un élégant sommier de lit avec poteaux en métal, témoignent du faste du train de vie de ses habitants (cliché de l'auteur, juillet 2019).

modèle[s] de produits riches », ce, non seulement pour servir d'exemple aux populations locales et permettre aux chefs de «jouir désormais d'une large aisance » - consubstantielle à l'exercice d'une autorité digne de ce nom - mais aussi pour que les chefs «soient de moins en moins tentés de se procurer des ressources en prélevant des tributs ou en imposant des amendes ${ }^{57}$. Il semble qu'Obodji Soboa bénéficiât de ces moyens, ayant été «chargé par l'administration de diriger la campagne pour la propagation de la culture du cacao et du café à Agboville », dans une région fertile située au sud de la «boucle du cacao »- nouvel or brun du pays -, correspondant au cercle de Dimbokro ${ }^{58}$. Mais il n'est pas sûr qu'il s'abstînt de prélever des prestations dues au chef selon la coutume, ou par simple usage de la persuasion ou de la force : Obodji Soboa avait la réputation de gérer son pays de main de fer et d'avoir un caractère impérieux.

Obodji Soboa développa plusieurs plantations personnelles de café et de cacao. Sur sa seule plantation de Babiahan (où avait lieu son pèlerinage) travaillaient à la dure plus de deux cents manœuvres, nourris mais non rémunérés $^{59}$ : soit du travail forcé, gratuit ou peu coûteux. Louis-Gustave Binger commentait lors de sa tournée en Côte d'Ivoire en 1927 : «Obodji n'est pas seulement resté un personnage politique influent : il a bien vite reconnu qu'au point de vue économique, il était possible d'obtenir des résultats inattendus. Il a fait des plantations de cacao et de café se chiffrant par quelques dizaines de 
mille pieds. Il possède plusieurs camions [quatre] transportant des produits au terminus du chemin de fer. Lui-même m'a fait les honneurs d'une promenade en auto : une Dodge, SVP ! L'administration me confia ceci : les revenus d'Obodji dépasseraient annuellement de beaucoup 100000 francs ${ }^{60}$ !!! »

En août 1927, Obodji fondait par ailleurs la «Compagnie commerciale de l'Agnéby », établissement de commerce de bétail entre le Soudan [Mali], la Haute-Volta et la Côte d'Ivoire, basé à Agboville. Pour l'anecdote, comme la coutume akan l'exige des chefs ${ }^{61}$, Obodji Soboa foulait rarement le sol de ses pieds nus et portait toujours des sandalettes. «Il fit venir à cet effet spécialement deux ouvriers cordonniers de Kumasi (Ghana). » Ces sandales furent commercialisées en Côte d'Ivoire, où on les appela « Abodjé ». «Incontestablement », comme l'écrit Frédéric Grah Mel déjà cité, Obodji Soboa «faisait partie du gotha financier de l'époque ${ }^{62}$. »

Défense des intérêts économiques des planteurs africains. Obodji Soboa était membre du Conseil d'agriculture et d'industrie d'Abidjan. Au début des années 1930, dans le contexte d'après la crise de 1929, il fit suite à une initiative lancée par le roi Boua Kouassi dans l'Indénié, en réunissant à son tour les producteurs africains de cacao du cercle d'Agboville, pour faire pression contre l'entente scellée entre les maisons de traite européennes et obtenir des cours plus rémunérateurs - les prix au kilo différaient selon qu'ils provenaient d'une plantation européenne ou africaine. L'historien de l'économie Jean-Baptiste Seka écrit : «Des délégations sont constituées pour rencontrer l'administrateur du cercle qu'Obodji Soboa ne craint pas de mettre directement en cause ; des pétitions sont adressées au gouverneur de la colonie et à celui de l'AOF ${ }^{63}$. » Mais les pressions exercées par l'administration coloniale pour faire monter les prix africains des matières premières échouèrent devant la détermination des planteurs européens à sanctuariser leurs privilèges.

Ma documentation est ténue sur la suite et mériterait d'être étayée. Il ne semble pas qu'Obodji Soboa, alors malade (détails ci-après), ait joué un rôle important dans la fondation du Syndicat agricole africain, premier grand mouvement syndical ivoirien dont Félix Houphouët-Boigny prit la tête. À Agboville, Gabriel Dadié, grand planteur installé dans la région depuis 1927 et proche compagnon d'Houphouët-Boigny, y joua un rôle autrement déterminant ${ }^{64}$. Il

60. Binger (1938, p. 254-255). L'article de Yavo (1957) serait illustré d'une photo d'Obodji Soboa avec sa Dodge, mais je n'ai pas réussi à trouver la revue dans laquelle il est paru.

61. Niangoran-Bouah (1973), Perrot (2005).

62. Grah Mel (2003, p. 268).

63. Seka (2018, p. 221). Toutes informations de ce paragraphe reprises de cette source.
64. Joseph Anoma, successeur d'Houphouët-Boigny à la tête du SAA, avait également des plantations en pays abbey : le chef Obodji Soboa lui avait cédé des terres de son frère Meney après sa mort à Dakar (communication avec Jean-Noël Loucou le 7 octobre 2019, d'après un entretien de Joseph Abo Kobi avec Joseph Anoma en 1983).

65. Le chef François M'Bassidjé, successeur d'Obodji Soboa en 1944 (ci-après), contribua aussi au financement du SAA.

66. Documents d'archives de Dakar tirées du fonds Niangoran-Bouah. 67. Entretiens à Agboville et Yappi Doffou (2017, p. 76-77). Indépendamment, Obodji fut aussi lésé de son immeuble à Abidjan. 68. Trichet (1995, p. 176).

69. Lettre du chef Obodji Soboa au commandant de cercle de l'Agnéby, Agboville, 29 juillet 1940 (archives de Léonard Obodji). 
est vraisemblable, en revanche, qu'Obodji Soboa ait soutenu le SAA au moment de sa création à Agboville le 10 juillet 1944, ne serait-ce que financièrement ${ }^{65}$.

\section{Le temps des épreuves : faillite, cécité et destitution (1938-1944)}

Au soir de sa vie, le chef Obodji Soboa souffrit trois grands revers. À partir de 1938, l'administration se fit nettement plus critique envers son ancien allié, tout à la fois pour son indépendance d'esprit - «il n'hésite pas, le cas échéant, à porter des accusations calomnieuses contre les fonctionnaires européens », lit-on dans un rapport - pour le sectarisme de « son mouvement akéïste » dont l'administration estimait qu'il tirait abusivement profit, et pour une affaire d'empoisonnement sur un chantier au port d'Abidjan à laquelle il aurait été mêlé. En 1939, le chef supérieur fit «l'objet d'une active surveillance » de la part de l'administration. En avril 1939, une note déplorait le « sectarisme dont font preuve les initiés de la religion Aké, dont le chef supérieur Obodji Soboa est le grand prêtre, vis-à-vis des autres confessions ${ }^{66}$ ».

Dans le même temps, la «Société de prévoyance sociale», la banque d'Obodji Soboa, fit faillite, à la suite, dit-on, d'une escroquerie des partenaires américains qui firent main basse sur sa réserve en or ${ }^{67}$. Augustin Apété raconte que le choc de la nouvelle fut si grand qu'Obodji Soboa souffrit sur le champ de graves problèmes de vue - accident vasculaire cérébral ? - et finit par devenir aveugle. À Agboville, les gens disaient, en anglais, qu'Obodji était bankrupt. Obodji dépêcha à Dakar son frère Meney, qui gérait ses affaires à Bassam, pour enquêter sur l'affaire. Malheureusement, Meney y tomba malade et mourut. Dès avril 1940, le coutumier de la mission catholique d'Agboville rapportait : «Réouverture du village de Loviguié [village de Ntakpé Soboa], village où les pères n'allaient plus par suite du départ des jeunes chrétiens fuyant les nombreuses vexations des Akés. Leur chef (Money) [Meney], principal instigateur de ces troubles, étant mort vers septembre 1939. Les jeunes gens reviennent ${ }^{68}$. »

En 1940, le chef des Abbey était désormais incapacité par sa cécité. Dans une lettre poignante, le 29 juillet 1940, il informa le commandant de cercle de l'Agnéby qu'en conséquence de « son triste sort »- «je suis formidablement mal aux yeux, je ne peux faire aucun mouvement »- il se ferait désormais « représent[er] nuit et jours [sic] à [s]on nom, auprès de l'administrateur du cercle, dans le bureau du Comisseria [sic], ou à la [illisible : gendarmerie ?] pour répondre toutes questions de l'administratif qui concernant du pays $[$ sic] », par « [s]es deux représentants »: Jules [Adagba] Obodji (son fils, planteur) et Mosso André [Mossôh Andrain] (son neveu, lettré, qui avait lu la note dans le coffret en argent le jour de sa réception miraculeuse, voir ci-avant) ${ }^{69}$.

La suite des événements gagnerait à être éclaircie. Dans le récit qu'en font les archives surgit la figure d'Emmanuel [Indikeu] Soboa, premier fils du chef abbey, ancien étudiant en France, ancien militaire des troupes coloniales, qui se faisait passer comme « suppléant du chef supérieur ». Un rapport de 1944 relate : «Il a intrigué d'abord dans le but de faire relever de leurs fonctions 
plusieurs chefs et de les faire remplacer par d'autres inféodés à la religion paternelle. Puis après sa démission de ses fonctions de commis auxiliaire de l'administration en septembre 1940, Emmanuel Obodji a intensifié son agitation en s’immisçant de plus en plus dans les affaires de chefferie. L'administration réagit en brisant l'opposition des notables qui s'étaient fait les instruments de la politique personnelle d'Obodji et en suspendant de ses fonctions le 16 janvier 1942 le chef supérieur des Abbey. Après l'éviction de son père [qui ne semble pas avoir été actée], les intrigues d'Emmanuel Obodji n'en persistèrent pas moins, tendant à nuire par tous les moyens aux adversaires de sa famille. C'est ainsi que sur dénonciations injustifiées et faux renseignements de sa part, des agents de la Brigade mobile de police d'Agboville, le 12 septembre 1943, arrêtèrent, au grand mécontentement des populations abbeys de l'endroit, plusieurs chefs de quartiers et notables qui durent être relaxés quelques heures plus tard. » À la suite de ces incidents, il fut décidé en 1944 qu’Emmanuel Soboa serait mis « en résidence obligatoire dans une localité de Haute-Côte d'Ivoire » [Haute-Volta] pour cinq ans ${ }^{70}$. Obodji Soboa, qui portait toujours le titre de chef, tenta de «créer une certaine agitation » contre cette sanction. «Agitation sans conséquence », tranchait l'administration, « la famille d'Obodji ayant peu à peu perdu de son prestige ${ }^{71}$. »

Au mois d'avril 1944, l'inspecteur des affaires administratives se rendit dans le cercle d'Agboville pour trancher cette affaire. S'en suivit la destitution du chef Obodji Soboa le 24 du mois ${ }^{72}$. L'État colonial imposa François Eddo M'Bassidjé, premier secrétaire d'Obodji, du canton tioffo, comme nouveau chef supérieur des $\mathrm{Abbey}^{73}$.

\section{Le temps de l'ombre : parrainage politique discret et décès (1945-1952)}

Obodji Soboa connut une forme de mort sociale avant sa mort. Après guerre, avec les transformations politiques en cours dans les colonies, les chefs traditionnels perdirent de leurs prérogatives auprès de l'État colonial ${ }^{74}$. De nouvelles élites intellectuelles prirent les devants du mouvement nationaliste. Obodji Soboa, quoique d'une autre époque et défait à tous égards, a néanmoins soutenu

70. $A N S, A P(G G) 1944$, rapport du 19 janvier 1944 au gouvernement général de l'AOF, avec projet d'arrêté portant résidence obligatoire d'Emmanuel Soboa en Haute-Côte d'Ivoire pour cinq ans. D'après la famille Obodji, Emmanuel Soboa, bon vivant, dépensier, n'a pas été à la hauteur des espérances que son père avait investies en lui pour qu'il lui succède.

71. ANS, 2G/44-132, page 3 d'un rapport partiellement photocopié (sans page de date) trouvé dans les archives de Niangoran-Bouah.

72. La date de destitution du 24 avril 1944 figure dans Niangoran-Bouah (1987).

73. Né en 1895 à Grand-Yapo, M'Bassidjé «débuta comme commis pointeur au chemin de fer Abidjan-

Niger " (Pairault, 1971, p. 63). Il devint un chef aisé mais sa fortune

n'atteignit pas celle de son prédécesseur.

74. En particulier, les chefs avaient administré la prestation du travail forcé, aboli en 1946. Voir Keese (2010, p. 11).

75. Grah Mel (2003, p. 268 et 270). 76. Ibid., p. 255, s'appuyant sur des archives de 1950.

77. CAOM, FM 1AffPol/2174/8, Péchoux, gouverneur de Côte d'Ivoire, à Béchard, gouverneur général de l'AOF ( $\left.n^{\circ} 1122 / A P\right)$, 5 juillet 1949 et FM 1AffPol/2174/8, Béchard à Coste-Floret, ministre de la France d'outre-mer ( $n^{\circ} 680 /$ INT/ AP/2), 4 août 1949. Sources citées dans Keese (2010, p. 20). 
l'émergence politique de Félix Houphouët-Boigny en Côte d'Ivoire. Il affirma avoir dépensé plus d'un million de francs pour l'élection d'Houphouët-Boigny à l'Assemblée constituante en octobre 1945 (sa faillite lui avait donc laissé de beaux restes) ${ }^{75}$. Kouamé Adingra, fils du chef supérieur des Abron Kouadio Adjoumani, grand planteur à Bondoukou, n'était pas favorable à ce qu'Houphouët-Boigny soit choisi comme candidat africain à la députation en 1945 . Il expliqua « qu'il avait cependant soutenu sa candidature à la députation par esprit de solidarité avec le chef supérieur d'Agboville qui pensait HouphouëtBoigny seul capable de les défendre parce qu'il était lettré ${ }^{76}{ }$. Obodji Soboa avait donc conservé de l'influence auprès de ses pairs même après sa destitution.

En 1949, un rapport du gouverneur Péchoux faisait état qu'un « groupe considérable d'habitants » relevant de la chefferie abbey souhaitait voir le nouveau chef supérieur François Eddo M’Bassidjé destitué au profit de son prédécesseur, et sollicitait l'appui du Rassemblement démocratique africain (RDA), le parti d'Houphouët-Boigny ${ }^{77}$. La note qualifiait M'Bassidjé de «hautement impopulaire ». La mobilisation correspondait-elle au retour d'Emmanuel Soboa de ses années en résidence obligatoire loin d'Agboville ? Quoi qu'il en fût, l'affaire resta sans suite. Emmanuel Obodji est mort en 1951, puis Obodji Soboa le 7 juillet 1952.

\section{Un héritage en miettes}

Le chef Obodji Soboa perdit successivement sa fortune et son pouvoir. Il ne put, non plus, préserver son héritage religieux. Le catholique François Eddo M'Bassidjé n'a pas repris pas le flambeau de la religion d'Aké $O f f o$ : il contribua au contraire à sa destruction violente. Le prédicateur akéiste d'Obodji Soboa que rencontra Georges Niangoran-Bouah lui fit ce récit : «Quand Monsôh Andrin prit la feuille [avec les écritures] dans le boîtier en argent, il lut aussi : “Obodji Soboa fera son travail pendant longtemps, jusqu'à ce qu'arrive le temps où il ne pourra plus trouver de prédicateur, où plus personne ne voudra faire le travail. À ce moment-là, il faudra arrêter la religion.” L'Église - poursuit l'interlocuteur de Niangoran-Bouah - avait une structure hiérarchique, avec Obodji Soboa à sa tête, et sous ses ordres, des prédicateurs qui allaient dans les villages ; tous se retrouvaient les samedis pour prier. Ces prédicateurs devaient passer devant Obodji Soboa et lui jurer fidélité, même s'ils devaient rencontrer des difficultés ou être persécutés. Puis ils buvaient l'eau de Dieu et étaient consacrés. Ces prédicateurs comptaient sur Obodji Soboa pour les défendre, mais quand il est tombé malade, le rempart est tombé. C'est là que François M'Bassidjé s'est levé. François et Achi Ketta, son notable, sont allés dire aux prédicateurs d'arrêter tout le travail spirituel d'Aké [...]. On a demandé aux prédicateurs de casser les églises. Les prédicateurs qui n'ont pas voulu casser leurs églises et qui passaient leur temps à danser ont été emmenés à Yapo [GrandYapo, village d'origine M’Bassidjé]. Les prédicateurs arrêtés, on a détruit leurs églises [celle de la «montagne » de Babiahan aussi, où se tenait le pèlerinage : 
il n'en reste aucune trace]. La pratique de la religion a été interdite. C'est tout cela qui a fait que les Abbey ont abandonné l'Église d'Aké $O f f o^{78}$. »

La répression contre le culte d'Obodji-Aké est venue non de la force coloniale mais de l'ancien allié qui, devenu chef, a cherché à saper la puissance de son prédécesseur y compris - voire surtout - au plan des forces de l'invisible. Amos Djoro rapporte qu'après 1946, date de création du Parti démocratique de Côte d'Ivoire (PDCI) dirigé par Houphouët-Boigny, John Ahui, autre héritier du prophète Harris en pays ébrié autour d'Abidjan et plus tard fondateur de l'« Église du Christ, Mission harriste », défenseur de la cause nationaliste défendue par Houphouët-Boigny et de l'africanisation du christianisme contre les missions européo-centrées catholiques et protestantes, «vint au secours des fidèles de Bodjui Aké et de Obodji Soboa, au nom de l'africanité » ${ }^{79}$. Il en est resté une petite communauté. D’après le recensement général de la population et de l'habitat de 2014, près de 11000 Abbey se déclaraient alors harristes, soit $5 \%$ de la population totale de ce groupe.

Après la chute de la maison Obodji, les missions catholiques et protestantes réinvestirent rapidement le pays abbey. Les Églises issues des missions et de nouvelles Églises pentecôtistes y sont aujourd'hui largement majoritaires au plan démographique.

Alors qu'au temps de son pouvoir, Obodji Soboa avait eu de bonnes relations avec son premier secrétaire, François M’Bassidjé, qui avait même prénommé l'un de ses fils Obodji, les relations entre les familles M'Bassidjé et Obodji se dégradèrent ensuite durablement. Le chef supérieur M’Bassidjé est décédé le 19 mai 1971 après vingt-sept ans de règne. Il est enterré à Obodjikro, à trois cents mètres d'Obodji Soboa. Mais, après sa mort, dix ans après l'indépendance, dans un contexte où le président Houphouët-Boigny souhaitait la disparition de la chefferie cantonale et le non-remplacement des chefs décédés, les chefs et notables abbey ne purent se mettre d'accord sur un successeur. Depuis lors, la chefferie abbey a renoué avec une gestion décentralisée de l'autorité coutumière.

\section{Conclusion : une mémoire oubliée}

En mai 2015, plus de soixante ans après la mort d'Obodji Soboa, le président Alassane Ouattara - installé au pouvoir en 2011, il allait être réélu au scrutin

78. Enregistrement audio d'une conversation entre Niangoran-Bouah et un prédicateur de la religion Obodji-Aké à Laouguié, en langue abbey, n.d. Le prédicateur raconte que quand il découvrit la répression qui s'était abattue sur la religion d'Aké Offo, il informa M'Bassidjé qu'il continuerait, pour sa part, d'exercer le culte contre vents et marées ( je m'en vais danser »), ce que
M'Bassidjé lui permit d'abord à Séguié puis à Laouguié, foyer résiduel du culte.

79. Amos Djoro (1992, p. 463)

80. Exception faite des efforts inaboutis de Georges NiangoranBouah, dont l'étude sur l'histoire des Abbey n'a pas été publiée. En 1997, Niangoran-Bouah accueillit à Agboville le président Henri Konan Bédié, successeur
d'Houphouët-Boigny, lors d'une tournée d'État. Bédié et NiangoranBouah s'étaient connus du temps de leurs études à Bordeaux. Bédié proposa à Niangoran-Bouah de soumettre à la présidence le projet de transformer la concession d'Obodji Soboa en musée, mais le coup d'État de 1999 qui renversa Bédié en sonna le glas (communication avec Léonard Obodji, 13 octobre 2019). 
d'octobre 2015 - faisait une tournée officielle dans l'Agnéby, sur un air de précampagne électorale. À cette occasion, comme cela se fait habituellement, des autorités traditionnelles d'Agboville le nommèrent « chef supérieur des Abbey » à titre honorifique, avec comme nom de règne « Nanan Obodji Soboa II ». La figure d’Obodji Soboa reste vénérée par certains Abbey : le marché d’Agboville porte toujours son nom, comme le vieux quartier abbey d'Obodjikro. Pour l'essentiel, toutefois, la mémoire collective l'a depuis longtemps oublié. Son personnage, l'histoire de sa vie, sa tombe, son palais, n'ont fait l'objet d'aucune appropriation patrimoniale, qui eut pu servir de catalyseur pour valoriser la place des Abbey dans le roman national ${ }^{80}$. De fait, l'épisode le plus connu de l'histoire des Abbey est la révolte anticoloniale de 1910, dans laquelle la participation d’Obodji Soboa et de son père, Ntakpé Soboa, est très peu connue, et, pour peu qu'elle le soit, plutôt dévalorisée eu égard à la geste des héros africains de la résistance à l'impérialisme européen.

Assurément, le portrait d'Obodji Soboa qui émerge des sources éparses et lacunaires consultées est une esquisse en clair-obscur, alternant ombre et lumière, avec un flanc sombre et du panache dans un halo de mystère. De tous les chefs coutumiers de la Côte d'Ivoire coloniale, Obodji Soboa fut celui qui associa le plus étroitement les fonctions politiques, économiques et religieuses. Il sut préserver l'autorité villageoise coutumière que son père exerçait déjà avant 1905 par la force physique, une certaine richesse et la religion traditionnelle. Il sut la transformer et l'élargir considérablement en tirant parti des espaces d'initiative ouverts par le réaménagement colonial du « commandement indigène ». Il sut augmenter sa fortune en tirant parti des niches ouvertes par l'économie coloniale capitaliste, en investissant simultanément dans les finances, le commerce, l'agriculture. Il le fit avec beaucoup d'intelligence opportuniste et d'audace inspirée. De tous les entrepreneurs prophétiques ivoiriens, Obodji Soboa fut aussi celui qui mêla le plus d'influences religieuses à sa nouvelle Église : protestante-harriste-akéiste, catholique, traditionnelle et peut-être islamique. Même si son entreprise syncrétique fut sans suite, elle connut, pour un temps, un succès indéniable, répondant sans doute à des attentes intimes et collectives chez ses administrés. Obodji Soboa fut un self-made-man d'une saisissante inventivité polyvalente : l'inventeur, en partie, de son propre destin, jusqu'à la rencontre avec sa part tragique. Il fit coexister salut religieux, richesse matérielle et domination politique sans contradiction aucune, comme souvent à l'époque précoloniale, selon sa propre herméneutique, malgré ou pardelà les contraintes exogènes de l’État colonial.

Obodji Soboa ne fit pas pour autant l'unanimité. Il ne la fit pas auprès de l'administration coloniale, qui, après avoir longtemps salué son soutien à la France, finit par se plaindre de ses propos critiques et s'inquiéta de sa puissance religieuse et matérielle. Le chef devenu aveugle, l'administration le destitua et dénia à son fils son droit de succession. Obodji Soboa ne fit pas non plus l'unanimité chez les Abbey, canton abévé excepté. Son ralliement aux Français dans la révolte de 1910 fut vécu par certains comme une trahison, notamment 
dans le canton morié (son père, Ntakpé Soboa, n’avait pas non plus catalysé l'unanimité des Abbeys lors de la révolte de 1905). Sa nomination comme chef supérieur par les Français s'est s'imposée aux chefs abbey de rang inférieur avec des grincements de dents, voire de la rancœur. L'exercice assumé de son pouvoir sur ses sujets africains put être vécu comme une domination autoritaire : ainsi, les prélèvements financiers (telles les sommes exigées pour la construction de l'église catholique en 1926), le travail sans salaire sur ses plantations, les contraintes religieuses discriminatoires en faveur de son culte d'Aké Offo, etc. Sa domination sans partage engendra en sourdine des velléités de résistance, qui firent surface en force quand la puissance du chef s'effondra. La mémoire d'Obodji Soboa ne put, par suite, être retravaillée collectivement pour servir de modèle endogène identificatoire, prototypique et simplifié, à destination des nouvelles générations, afin de valoriser le génie des Abbey dans l'histoire et, par suite, amener les jeunes à s'approprier leur passé et à s'engouffrer sur le chemin défriché par l'ancêtre glorieux, en inscrivant leur propre nom sur la page vierge de l'histoire du temps présent.

Obodji Soboa a donc légué à sa société un héritage incertain, voilé. Pour l'heure, la société abbey semble avoir choisi de ne pas actualiser la mémoire du fait que le lignage Soboa initia une expérience de gestion centralisée de la chefferie coutumière, poursuivie par un chef moins charismatique mais à la vie longue, François M'Bassidjé. L'époque est pourtant au retour de la chefferie traditionnelle centralisée dans l'espace étatique de la République de Côte d'Ivoire. Le gouvernement d'Alassane Ouattara a en effet proposé une nouvelle constitution, acceptée par référendum en 2016, instituant une « Chambre nationale des rois et chefs traditionnels ». Ce dispositif inscrit dans la Loi fondamentale annule et remplace l'arrêté du 10 octobre 1934 qui avait formalisé le « commandement indigène ». Il prévoit, entre autres, la rémunération des rois et chefs de cantons, comme à l'époque coloniale (ce financement s'était interrompu après l'indépendance) -, ce qui fait craindre à d'aucuns une instrumentalisation politique de cette chefferie notamment à des fins électorales. Historiquement, les modalités traditionnelles d'exercice de l'autorité politique varient grandement d'une société et d'une région à l'autre en Côte d'Ivoire. Mais depuis les prémices coloniales et de manière accélérée depuis la mise en place de la nouvelle Chambre en 2016, le modèle de la royauté akan (typiquement agni) tend à s'imposer comme modèle générique de chefferie à toutes les sociétés de la Côte d'Ivoire, même dans les communautés traditionnellement sans État comme à l'ouest en pays krou ${ }^{81}$. Les Abbey, pour leur part, n'ont pas encore tranché la question.

81. Sur le retour des rois et des autorités traditionnelles en Afrique depuis les années 1980, voir par exemple Perrot et Fauvelle (2003) et Perrot (2006 et 2009). Je chéris la mémoire de Claude-Hélène-Perrot à qui cet article est dédié, sa généreuse amitié et ses encouragements sans faille : merci de m'avoir introduit à I'histoire des religions traditionnelles et des mondes akan de la Côte d'Ivoire; que la terre de tes ancêtres franc-comtois, agni et éotilé te soit légère! 


\section{Bibliographie}

Amon d'Aby, F.-J. (1958),

Le problème des chefferies traditionnelles en Côte d'Ivoire, Abidjan, Imprimerie Jemmapes.

Amos Djoro, E. (1992), « Les conséquences sociologiques et philosophiques du harrisme en Côte d'Ivoire (harrisme et sociétés lagunaires) ", thèse d'histoire, université de Paris-4.

Arnaut, K. (2008), "Les "hommes de terrain". Georges NiangoranBouah et le monde universitaire de l'autochtonie en Côte d'Ivoire", Politique africaine, vol. CXII, $\mathrm{n}^{\circ} 4$, p. 18-35.

Augé, M. (1969), Le rivage alladian. Organisation et évolution des villages alladian, Paris, Orstom.

Binger, L.-G. (1938), Une vie d'explorateur. Souvenirs extraits des Carnets de route, ou notés sous la dictée par son fils Jacques Binger et commentés par René Bouvier et Pierre Deloncle, Paris, Fernand Sorlot.

Bureau, R. (1996), Le prophète de la lagune. Les harristes de Côte d'Ivoire Paris, Karthala.

Chivas-Baron, C. (1939), Côte d'Ivoire, Paris, Larose.

Deschamps, A. (1950), «Le christianisme et ses déformations à la Côte de Guinée », mémoire, Paris, Enfom.

Dozon, J.-P. (1995), La cause des prophètes. Politique et religion en Afrique contemporaine, suivi par $L a$ leçon des prophètes par Marc Augé, Paris, Seuil.

Duchesne, V. (2002), « Georges Niangoran-Bouah (1935-2002)", Journal des africanistes, vol. LXXII, $n^{\circ} 1$, p. 268.

Ekanza, S.-P. (2006), Côte d'Ivoire. Terre de convergences et d'accueil $\left(x v^{e}-x I x^{e}\right.$ siècles), Abidjan, Éditions du CERAP.

Gonnin, G., Allou, R.K. (2006), Côte d'Ivoire. Les premiers habitants, Abidjan, Éditions du CERAP.
Grah Mel, F. (2003), Félix

Houphouët-Boigny. Biographie,

Paris, Maisonneuve et Larose,

Abidjan, Éditions du CERAP.

Grivot, R. (1955), "Agboville. Esquisse d'une cité d'Afrique noire", Études éburnéennes, $n^{\circ}$ 4, p. 84-107.

Guiral, M. (1976), « La pénétration française en pays abbey (1903-1911) et la révolte des Abbeys ", maîtrise d'histoire, université Paris-1.

Haliburton, G.M. (1971), The Prophet Harris. A Study of an African Prophet and his MassMovement in the Ivory Coast and the Gold Coast (1913-1915), Londres, Longman.

Hanretta, S. (2009), Islam and Social Change in French West Africa. History of an Emancipatory Community, Cambridge, Cambridge University Press.

Keese, A. (2010), "Understanding Colonial Chieftaincy from its Final Phase. Responses to the Crisis of an Institution in French-Ruled West Africa and Beyond (1944-1960) », Africana Studia, $n^{\circ} 15$, p. 11-28.

Lawrance, B.N., Osborn, E.L., Roberts, R.L. (2006), Intermediaries, Interpreters and Clerks. African Employees in the Making of Colonial Africa, Madison, University of Wisconsin Press.

Loucou, J.-N. (2012), La Côte d'Ivoire coloniale (1893-1960), Abidjan, Éditions FHB/Éditions du CERAP.

Niangoran-Bouah, G. (1973), "Symboles institutionnels chez les Akan ", L'Homme, t. XIII, n 1-2, p. 207-232.

Pairault, C. (1971), "Souvenirs de François M'Bassidjé ", Bulletin de liaison du Centre universitaire de recherches de développement, université d'Abidjan, n 1, p. 63-66

Perrot, C.-H. (2002), « Georges Niangoran-Bouah ", Cahiers d'études africaines, vol. XLII, n 4, p. 627-631.
Perrot, C.-H. (2005), « « Du visible à l'invisible : les supports du pouvoir en pays akan (Afrique de l'Ouest)", Bulletin du centre de recherche du château de Versailles, $n^{\circ} 2$

Perrot, C.-H. (2006), "Chefs traditionnels : le cas du sud-est de la Côte d'Ivoire ", Afrique contemporaine, $\mathrm{n}^{\circ} 217$, p. 173-184.

Perrot, C.-H. (2009), «Les autorités traditionnelles et l'État moderne en Afrique subsaharienne au début du xxI ${ }^{e}$ Siècle ", Cadernos de Estudos Africanos, $\mathrm{n}^{\circ} 16-17$, p. 15-33.

Perrot, C.-H., Fauvelle-Aymar, F.-X. (2003), Le retour des rois. Les autorités traditionnelles et l'État en Afrique contemporaine, Paris, Karthala.

Roux, A. (1971), L'Évangile dans la forêt. Naissance d'une église en Afrique noire, Paris, Cerf.

Seka, J.-B. (2018), « La gouvernance des crises économiques en Côte d'Ivoire. Cas de la crise commerciale de 1927-1935 ", Cahiers d'études africaines, $n^{\circ} 229$, p. 209-229.

Shank, D. (1994), Prophet Harris. The "Black Elijah" of West Africa (abrégé par J. Murray), Leiden, Brill.

Trichet, P. (1995), Côte d'lvoire. Les premiers pas d'une Église, vol. II, Abidjan et Paris, Procure des missions africaines.

Viti, F. (2016), " Les quatre morts du colon Rubino (Côte d'Ivoire, janvier 1910) », Le Journal des africanistes, vol. LXXXVI, $n^{\circ} 1$, p. 329-339.

Yapi Doffou, C. (2017), De la révolte des Abbey à l'assassinat d'Ernest Boka, un devoir de vérité !, Abidjan, Éditions Biessodji.

Yavo, V. (1957), « Sa majesté Obodji Soboa et la chefferie chez les Abbeys ", Traits d'union, $n^{\circ} 15$, p. 30-35.

Yeo, S. (2009), Les États-nations face à l'intégration régionale en Afrique de l'Ouest. Le cas de la Côte d'Ivoire, Paris, Karthala. 